\title{
nate \\ Graphene Oxide Synthesis, Properties and Characterization Techniques: A Comprehensive Review
}

\author{
Dimitrios G. Trikkaliotis, Achilleas K. Christoforidis, Athanasios C. Mitropoulos and George Z. Kyzas *D \\ Department of Chemistry, International Hellenic University, GR-65404 Kavala, Greece; \\ odimtri@gmail.com (D.G.T.); achrist@teiemt.gr (A.K.C.); amitrop@chem.ihu.gr (A.C.M.) \\ * Correspondence: kyzas@chem.ihu.gr; Tel.: +30-2510-462218
}

\section{check for}

updates

Citation: Trikkaliotis, D.G.; Christoforidis, A.K.; Mitropoulos, A.C.; Kyzas, G.Z. Graphene Oxide Synthesis, Properties and

Characterization Techniques: A Comprehensive Review. ChemEngineering 2021, 5, 64 https://doi.org/10.3390/ chemengineering5030064

Academic Editors: Alírio

E. Rodrigues and Andrew S. Paluch

Received: 17 August 2021

Accepted: 16 September 2021

Published: 17 September 2021

Publisher's Note: MDPI stays neutral with regard to jurisdictional claims in published maps and institutional affiliations.

Copyright: (C) 2021 by the authors. Licensee MDPI, Basel, Switzerland. This article is an open access article distributed under the terms and conditions of the Creative Commons Attribution (CC BY) license (https:// creativecommons.org/licenses/by/ $4.0 /)$.

\begin{abstract}
The unique properties of graphene oxide (GO) have attracted the attention of the research community and cost-effective routes for its production are studied. The type and percentage of the oxygen groups that decorate a GO sheet are dependent on the synthesis path, and this path specifies the carbon content of the sheet. The chemical reduction of GO results in reduced graphene oxide (rGO) while the removal of the oxygen groups is also achievable with thermal processes (tpGO). This review article introduces the reader to the carbon allotropes, provides information about graphene which is the backbone of GO and focuses on GO synthesis and properties. The last part covers some characterization techniques of GO (XRD, FTIR, AFM, SEM-EDS, $\mathrm{N}_{2}$ porosimetry and UV-Vis) with a view to the fundamental principles of each technique. Some critical aspects arise for GO synthesized and characterized from our group.
\end{abstract}

Keywords: graphene oxide; synthesis; characterizations; Hummers method; properties

\section{Introduction \\ 1.1. Carbon and Allotropes}

Carbon is a chemical element with chemical symbol C, atomic number 6 and atomic weight $12.011 \mathrm{u}$. It is located in group IV A in the periodic table of elements and belongs to nonmetal. Each carbon atom has four electrons that can be bonded, so its valence is usually 4. Carbon is one of the few elements found since ancient times. Carbon $\left({ }_{6}^{12} \mathrm{C}\right)$, one of the most abundant elements in nature, participates in many fundamental systems and processes, such as DNA formation and photosynthesis [1]. Allotrope refers to a simple substance composed of the same chemical element but with different structure and morphology. There are several allotropic forms of carbon, the most common of which are graphite, diamond and amorphous carbon. There are great differences in physical properties, including appearance, hardness, conductivity and so on. Carbon has three isotopes, the ${ }_{6}^{12} C$ and ${ }_{6}^{13} C$ that are stable and the radiocarbon ${ }_{6}^{14} C$ with half-life 5730 years. Graphenes, diamonds, fullerenes, graphites, quantum dots, nanohorns and nanotubes are all carbon allotropes. Nowadays, graphene is considered the archetypal structure of all carbon nanoforms. The graphene materials family also include the graphene flakes, graphene oxides and many others [2]. Coal is an amorphous, thermodynamically unstable carbon that is classified as anthracite ( $90 \%$ carbon), lignite (60-70\% carbon) and peat (50\% carbon).

\subsection{Fullerenes}

Fullerenes $\left(\mathrm{C}_{60}\right)$, discovered by Professors Kroto, Curl and Smalley in 1985 during simulations of carbon vapors at red-star atmosphere, are spherical cage-like fused-ring OD carbon structures of 20 hexagons and 12 pentagons with typical diameter $\sim 0.7 \mathrm{~nm}$. For this discovery, they awarded the Nobel Prize in Chemistry in 1996, while a few years earlier, in 1991, fullerene was the Molecule of the Year [3]. The hexagons have three double $\mathrm{C} \backslash \mathrm{C}$ bonds while the pentagons consist of single bonds. Surprisingly, fullerenes exist both in nature and interstellar space. Fullerene is the first symmetric nanostructure in carbon 
family and the most symmetrical molecule in the world [4]. Nowadays, there are fullerenes composed of 32 to 600 carbons. Fullerenes, also called buckyballs, took their name from the American architect Buckminster Fuller who first envisioned and created such geodesic domes. $\mathrm{C}_{60}$ s have face centred cubic lattices (FCC) and degrade at temperatures above $1000{ }^{\circ} \mathrm{C}$. Fullerenes are hydrophobic but display low aggregation tendency and require modification with hydrophilic moieties to become water-soluble [5]. On the other hand, fullerenes are soluble to organic solvents like chloroform, benzene and toluene. They act as gas filters and are excellent reinforcing compounds in applications that require high pressure resistance such as aircrafts and ships. Endohedral fullerenes encapsulate different species inside the hollow cage relatively easy being applicable to theranostic and drug carrier systems [6]. In addition, the external surface of the carbon cage can be functionalized through the $C \backslash C$ double bond cleavage [4,7] allowing fullerenes to cross the cell membrane and bind with mitochondria [8]. In the same way, fullerenes have been used for dermatological applications as antioxidant agents to treat acne and hydrate the skin [9]. Other research fields include hydrogen storage, catalysis, optoelectronics, electrodes, photosensitizers and organic solar cells; however, their production is still quite expensive [10]. The main methodologies for fullerenes production are (a) the evaporation and recondensation of graphite, (b) the combustion of hydrocarbons in sooting flames and (c) the microwave-induced $\mathrm{N}_{2}$ plasma [4].

A recent derivative of fullerene is the corannulene, also known as buckybowl, which is the smallest curved subunit of fullerene and consists of 20 carbons $\left(\mathrm{C}_{20} \mathrm{H}_{10}\right)$. While fullerene forms a stable hexaanion due to its property to stabilize six electrons on its surface ( 1 electron per 10 carbons in $\mathrm{C}_{60}$ ), corannulene forms a stable tetraanion and is more electron rich per carbon atom ( 1 electron per 5 carbons in $C_{20}$ ). Development of solar cells and photocatalysts with corannulene-based materials are studied due to the efficient energy transfer of these building blocks [11].

Multi-layered fullerenes, also known as carbon nano-onions (CNOs), were discovered by Iijima in 1980. CNOs are polyhedral quasi-spherical graphitic layers with interlayer distance $\sim 0.335 \mathrm{~nm}$. The number of the carbon atoms to each layer is calculated with the formula:

$$
C_{n}=C_{60} \cdot n^{2},
$$

where $\mathrm{n}$ is the corresponding layer.

Each layer might possess many defects and holes as well as heptagonal rings. The main synthetic methods of CNOs include (a) thermal annealing of nanodiamonds (NDs), (b) chemical vapor deposition (CVD), (c) arc-discharge, (d) ion implantation, (e) pyrolysis and (f) electron-beam irradiation. Depending on the preparation route, the resulting structures might vary in size (big or small), in shape (spherical or polyhedral), and in core (dense or hollow). Interestingly, during the thermal annealing of NDs, the CNOs are firstly transformed into spherical and then into polyhedral onions [12]. Table 1 summarizes the methods and properties of CNOs.

Table 1. Methods of CNOs synthesis [12].

\begin{tabular}{|c|c|c|c|c|}
\hline Method & Substrate & Condition & Size \& Shape & Yield \\
\hline $\begin{array}{l}\text { Electron- } \\
\text { beamirradiation }\end{array}$ & Amorphous carbon soot & - & $\begin{array}{l}\text { Pristine dense-core } \\
\text { spherical CNOs, ca. } \\
6-50 \mathrm{~nm}\end{array}$ & Low yield \\
\hline Annealing & NDs & $800-2100{ }^{\circ} \mathrm{C}$ & $\begin{array}{l}\text { Pristine dense-core } \\
\text { spherical CNOs, } \\
5-10 \mathrm{~nm}\end{array}$ & High yield \\
\hline Arc-discharge & $\begin{array}{l}\text { Amorphous carbon soot } \\
\mathrm{Ni} / \text { Al catalyst }\end{array}$ & $\begin{array}{l}\text { Arc discharge between } \\
2 \text { graphite } \\
\text { electrodes, water } \\
5000-6000 \mathrm{~K} \text { under } \\
\text { water }\end{array}$ & $\begin{array}{l}\text { High-quality spherical } \\
\text { hollowcore CNOs, } \\
\text { 15-25 nm } \\
\text { Pristine hollow-core } \\
\text { spherical CNOs } \\
\text { 5-50 nm }\end{array}$ & $\begin{array}{l}\text { Largequantities } \\
\text { Low yield }\end{array}$ \\
\hline
\end{tabular}


Table 1. Cont.

\begin{tabular}{|c|c|c|c|c|}
\hline Method & Substrate & Condition & Size \& Shape & Yield \\
\hline $\begin{array}{l}\text { Chemical vapour } \\
\text { deposition }\end{array}$ & $\begin{array}{l}\mathrm{CH}_{4}, \mathrm{~N}_{2} \\
\mathrm{CH}_{4}\left(60 \mathrm{~mL} \mathrm{~min}^{-1}\right) \\
\mathrm{N}_{2}\left(540 \mathrm{~mL} \mathrm{~min}^{-1}\right)\end{array}$ & $\begin{array}{l}\mathrm{Ni} / \mathrm{Al} \text { catalyst, } \mathrm{Ni} \\
\text { content }>60 \mathrm{wt} \%\end{array}$ & $\begin{array}{l}\text { Pristine hollow-core } \\
\text { spherical CNOs, } \\
5-50 \mathrm{~nm}\end{array}$ & Largequantities \\
\hline \multirow[b]{2}{*}{ Ion implantation } & carbon into $\mathrm{Cu}, \mathrm{Ni}$ substrate & $600-1000^{\circ} \mathrm{C}$ & $\begin{array}{l}\text { Pristine dense-core } \\
\text { spherical CNOs, } \\
\text { 15-200 nm }\end{array}$ & Low yield \\
\hline & Ag substrate & $>600^{\circ} \mathrm{C}$ & $\begin{array}{l}\text { Pristine dense-core } \\
\text { spherical CNOs, } \\
\text { 5-100 nm }\end{array}$ & Low yield \\
\hline \multirow{3}{*}{ Pyrolysis } & Phenol-formaldehyde & $\begin{array}{l}\text { Ferric nitrate catalyst, } \\
1000{ }^{\circ} \mathrm{C}\end{array}$ & $\begin{array}{l}\text { Pristine dense-core } \\
\text { CNOs, ca. } 40 \mathrm{~nm}\end{array}$ & Largequantities \\
\hline & Propane & $\begin{array}{l}\text { Propane/Oxygen flame } \\
\text { (1.8 stoichiometric } \\
\text { coefficient), } \mathrm{Al}\end{array}$ & $\begin{array}{l}\text { CNOs with many } \\
\text { by-product, } 10-25 \mathrm{~nm}\end{array}$ & Low yield \\
\hline & $\begin{array}{l}\text { Plastic wastes (polyethylene, } \\
\text { styrene, ethylene terephthalate) }\end{array}$ & 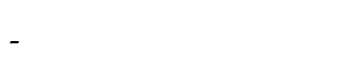 & $\begin{array}{l}\text { CNOs with many } \\
\text { by-product, } 50-70 \mathrm{~nm}\end{array}$ & Low yield \\
\hline
\end{tabular}

\subsection{Carbon Nanotubes (CNTs)}

Carbon Nanotubes (CNTs) were synthesized from Iijima just after the fullerenes at NEC laboratories in 1991. Nowadays, CNTs are synthesized by laser ablation, arc discharge and chemical vapor deposition [5]. CNTs are cylindrical 1D concentric tubes composed of hexagonal carbon structures, namely the Russian Doll model. The alternative model is called Parchment, where a single graphite layer is rolled around itself. Occasionally, the edges are closed by hemispheric structures like half-fullerenes. CNTs could be Single-, Double- or Multi- Walled with diameter 0.6-2.0 nm for SWNT and 2-100 nm for MWCNT, and a few micrometers in length. The length-to-diameter ratio could be up to $10^{8}: 1$. The distance between the layers is slightly larger than in graphite $(\sim 3.60 \AA)$ due to the curvature. CNTs are usually formed in bundles, while according to their orientation, which is specified by the chiral vector and its indices $(n, m)$, they behave either as metals or semi-conductors. A CNT is six times lighter than the corresponding steel and 100 times stiffer. The unique strength of CNTs derives from the chemical bonding which is composed entirely of $\mathrm{sp}^{2}$ bonds [13]. CNTs possess unique structural, optoelectronic, mechanical and physicochemical properties, with a specific surface area up to $3000 \mathrm{~m}^{2} / \mathrm{g}$ [14]. CNTs are selective sorbents, and have been used as fillers in polymers and structural materials such as cements (where the MWCNTs are more beneficial than SWCNTs), in hydrogen storage, as sensors and bio-sensors, and in drug delivery having the ability to carry or encapsulate the drug $[15,16]$. The background on synthesis, characterization and application of CNTs proved helpful in graphene research. CNTs are synthesized by catalytic decomposition of gaseous hydrocarbons and electric arc discharge. The two-step catalytic chemical vapor deposition method provides the highest aspect ratio and excellent purity. Common oxidizing agents of $\mathrm{CNTs}$ are $\mathrm{HNO}_{3}, \mathrm{H}_{2} \mathrm{O}_{2}$ and $\mathrm{KMnO}_{4}$. Surface modification of CNTs allows stabile dispersions in polar solvents avoiding the aggregation [17]. CNTs should not be confused with carbon nanofibers (CNFs), which consist of single or double layer graphitic planes. CNFs were discovered by Hughes and Chambers in 1889, but their structure was characterized by Radushkevich and Lukyanovich in 1950s [18]. Bioethics of CNTs are not yet determined. Experiments have shown that CNTs might leach after certain cycles, disrupt the metabolic functions of microbes and affect the aquatic life. In addition, CNTs might be responsible for inducing lung cellular proliferation and pulmonary inflammation. Broadly speaking, the agglomerated CNTs induce more toxicity than the well dispersed [13]. 


\subsection{Graphites}

Graphite (3D), widely known from the pencil invention in 1564, named by A. G. Werner in 1789 from the Greek "to draw/write", is formed when carbon atoms develop stacked honeycomb layers [8]. The usual stacking of graphite layers follows the Bernal model where every third carbon layer is at the same position (settlement $1212 \ldots$ ). The high stability of each layer is owned to the strong C-C covalent bonds, with bond length $\sim 0.142 \mathrm{~nm}$, while the weaker (orders of magnitude) van der Waals interactions in the c-direction hold the layers in a distance of $\sim 0.335 \mathrm{~nm}$ [19]. Each atom is connected in plane with three others under $\mathrm{sp}^{2}$ hybridization at $120^{\circ}$ (Figure 1). Graphite is less inert than diamond but thermodynamically more stable and is used in electrodes, resins, adhesives, pencils and lubricants. It is worth mentioning that graphite conducts electricity anisotropic, with the in-plane conductivity being $\sim 10^{4}$ times higher than the perpendicular. Especially, for energy storage applications (such as batteries), graphite electrodes are widely adopted, due to the fact that the higher graphitization degree leads to lower charge transfer resistance than conventional carbon materials [20,21]. In addition, graphite has the characteristics of strong oxidation resistance, good thermal insulation [Advanced Engineering Materials 16.5 (2014): 494-506] and corrosion resistance [22]. Natural graphite is classified to vein, flake and amorphous/microcrystalline. Vein graphite is the purest having carbon content over $90 \%$, but is mined in Sri Lanka only and consists of less than $1 \%$ of the global production. China, Korea, Canada, Brazil, Australia and Siberia have vast amounts of natural flake graphite, which is an inexpensive mineral, and the annual global production exceeds $10^{6}$ tons. Mechanical separation and flotation are typically used to remove heteroatom contamination followed by drying. Flake graphite is supplied in various mesh size and purity.

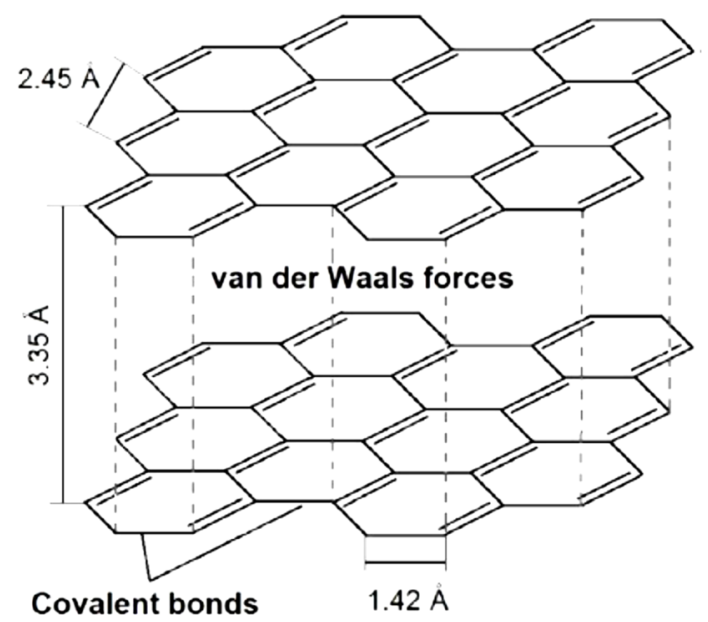

Figure 1. Graphite structure and van der Waals interactions between graphite layers [23].

\subsection{Graphenes}

\subsubsection{Graphene Properties}

The synthesis of graphene has a sincerely lower cost than the aforementioned carbonbased nanomaterials. The research community showed increased interest for investigation and modification of its properties. Graphene is highly tunable offering immense design capabilities [2]. In the beginning, Peierls and Landau stated that 1D or 2D crystalline materials cannot sustain their structure when the temperature rise [24,25]; hereafter, in 1947, Wallace first wrote about the structure and the unusual semi-metallic character of graphene [26], but it was Geim and Novoselov in 2004 who isolated and studied a single layer of graphite contradicting the view that graphite's mono-layers are thermodynamically unstable under ambient conditions [27]. They awarded the Nobel Prize in Physics in 2010 for their work; and, since then, graphene is considered the archetypal nanostructure of all carbon nanoforms. Other known 2D materials isolated after 2004 are the Boron-Nitride 
(BN) and Molybdenum-disulphide $\left(\mathrm{MoS}_{2}\right)$, with graphene-based publications being more than 100,000 till 2015, and the corresponding patents more than 14,000. Horizon 2020 is a European Union programme funded with 1000 million $€$ aiming to take graphene and other layered materials from the fundamental science to industrial and societal application [28,29].

Graphene is the thinnest known material, and the charge carriers could be more than $\mathrm{n}=10^{12} \mathrm{~cm}^{-2}$ possessing high mobility at low temperature $\left(\mu \approx 2 \times 10^{5} \mathrm{~cm}^{2} \mathrm{~V}^{-1} \mathrm{~s}^{-1}\right)$. It is worth mentioning that the mobility to silicon is $\sim 800 \mathrm{~cm}^{2} \mathrm{~V}^{-1} \mathrm{~s}^{-1}$ at room temperature. Graphene can be viewed as solid or a macromolecule with molecular weights (MW) more than $10^{7} \mathrm{~g} / \mathrm{mol}$. It has high thermal conductivity $\left(\mathrm{K} \approx 5 \times 10^{3} \mathrm{Wm}^{-1} \mathrm{~K}^{-1}\right)$ and low anisotropic thermal expansion coefficient, high optical transparency $(\sim 97.7 \%)$ and low reflectiveness $(<0.1 \%)$, large surface area $\left(\sim 2630 \mathrm{~m}^{2} / \mathrm{g}\right)$, superb mechanical properties $(\mathrm{E} \approx 1 \mathrm{TPa})$ including flexibility up to $30 \%$, high electrical conductivity $(\sim 20,000 \mathrm{~S} / \mathrm{cm})$, high stability in air atmosphere up to $400{ }^{\circ} \mathrm{C}$, and acts as a gas barrier $[8,28,30,31]$. All of these properties, which refer to an ideal single-layer graphene, make it attractive for a vast number of applications, including field effect transistors, sensors, electrodes, batteries and capacitors, composites, solar cells, hydrogen storage, displays, spintronics, drug delivery, desalination and water treatment and others [29,32-34]. Graphene has the potential to outclass the other carbon nanomaterials in many markets. It should be noticed that graphene monolayers are stabilized on support surfaces; otherwise, partial restacking and graphite-like structures will be formed [35].

Though, in real life, graphene layers are wavy and depend on the synthesis route, they possess defects, vacancies and impurities which unbrace the properties. These waves could seize up to $100 \AA$ in length and $5 \AA$ in height and result from the $C-C$ bond deformations. These deformations are responsible for the negative thermal expansion coefficient-graphene contracts when heated and expands when cooled (like water). Nevertheless, the repetitive wavy morphology imports energy gap at Fermi level which is necessary for electronic applications. Adsorption of molecules such as $\mathrm{H}_{2}, \mathrm{OH}$ and $\mathrm{H}_{2} \mathrm{O}$ introduce wavy structure. It has been reported that hydroxyls expand the neighboring bonds about $10 \%$. Graphene reconstructs the defected network when exposed to carbonaceous molecules, such as carbohydrates, as well as when bombed with carbon atoms. In addition, the graphene edges present zig-zag or arm-chair arrangement.

A special feature of carbon is its hybridization degrees. Each atom has six electrons that residence the $1 \mathrm{~s}, 2 \mathrm{~s}$ and $2 \mathrm{p}$ orbits. The four valence electrons which allocate the $2 \mathrm{~s}$ and $2 p_{x}, 2 p_{y}$ and $2 p_{z}$ orbits develop the covalent bonds in carbonaceous materials. Since the energy difference between the $2 p$ and $2 s$ zones is minor of the required energy for chemical bonds, the orbits are mixed forming hybrids of lower energy. The mixture of an s orbit with $\mathrm{n}=1,2$ or $3 \mathrm{p}$ orbits is called $\mathrm{sp}^{\mathrm{n}}$ hybridization. Graphene presents $\mathrm{sp}^{2}$ hybridization in plane, where the $s, p_{x}$ and $p_{y}$ orbits are combined forming three $\sigma$ orbits; and the interaction of these $\sigma$ orbits between neighboring carbons result in covalent $\sigma$ bonds which are responsible for the supreme mechanical properties [36]. The $p_{z}$ orbit is transversely positioned, and cannot interact with the $\sigma$ orbits when the plane is flat, but interacts with the neighboring $\mathrm{p}_{\mathrm{z}}$. The result of the $\mathrm{p}_{\mathrm{z}}$ interactions are the $\pi$ and $\pi^{*}$ state bands which are responsible for the graphene's electrical properties. The electron delocalization over the layer (formation of an electron cloud due to the $p_{z}$ interactions) blocks the passage through the aromatic rings even to small molecules such as $\mathrm{H}_{2}\left(\mathrm{~d}_{\mathrm{H} 2}=0.314 \mathrm{~nm}\right)$ and $\mathrm{He}$ $\left(\mathrm{d}_{\mathrm{He}}=0.28 \mathrm{~nm}\right)$ for pressures up to $5 \mathrm{~atm}$.

Graphene's structure is described as an infinite hexagonal network. The unit cell covers an area of $\sim 0.052 \mathrm{~nm}^{2}$ and consists of two non-equivalent atoms (forming bipartite lattice) with distance $\mathrm{a}_{\mathrm{cc}}=1.42 \AA$, which is the mean value of a single (C-C) and a double $(\mathrm{C}=\mathrm{C})$ covalent bond [1]. The primitive lattice vectors are defined as:

$\vec{a}_{1}=\left(\frac{3 a_{c c}}{2}, a_{c c} \frac{\sqrt{3}}{2}\right)$ and $\vec{a}_{2}=\left(\frac{3 a_{c c}}{2},-a_{c c} \frac{\sqrt{3}}{2}\right)$ forming $60^{\circ}$ angle where $\left|\vec{a}_{1}\right|=\left|\vec{a}_{2}\right|=2.46 \AA$, and the reciprocal-lattice vectors are defined as:

$$
\vec{b}_{1}=\frac{2 \pi}{3 a_{c c}}(1, \sqrt{3}) \text { and } \vec{b}_{2}=\frac{2 \pi}{3 a_{c c}}(1,-\sqrt{3}) \text { forming } 120^{\circ} \text { angle. }
$$


The reciprocal-lattice vectors contribute to Brillouin zone definition, where $\vec{G}_{10}$ and $\vec{G}_{01}$ correspond to $\vec{b}_{1}$ and $\vec{b}_{2}$, respectively. If $\Gamma(0,0)$ is the origin, the points $K, K^{\prime}$ and $\mathrm{M}$ specify the boundaries of Brillouin zone and exhibit high symmetry, while the energy dispersion at $K$ and $K^{\prime}$ points is responsible for the super-conductive properties of graphene as the conduction and valence bands cross at the Fermi level. The coordinates of $\mathrm{K}_{1}$ and $\mathrm{M}_{1}$ are:

$\mathrm{K}_{1}=\left(\frac{2 \pi}{3 a_{c c}}, \frac{2 \pi}{3 a_{c c} \sqrt{3}}\right)$ and $\mathrm{M}_{1}=\left(\frac{2 \pi}{3 a_{c c}}, 0\right)$.

There are 8 energy zones of graphene, four valence and four conductive bands, where the $\pi$ and $\pi^{*}$ result from the $\pi$ band while the other $6\left(\sigma\right.$ and $\left.\sigma^{*}\right)$ from the $\sigma$ bands. The unit cell consists of two carbon atoms; thus, the eight valence electrons are allocated to the four bands with the lower energy. The energy gap between $\sigma$ and $\sigma^{*}$ bands block the electron transition, but the $\pi$ band isotropic energy dispersion at the high symmetry points (K) allow the $\pi \rightarrow \pi^{*}$ transition. The electron speed near $\mathrm{K}$ points reach the $1 / 300$ of the light, about $10^{6} \mathrm{~m} / \mathrm{s}$. According to the tight-binding Hamiltonian model for electrons, which neglects interactions between atoms far from each other, the required transition energy to the first neighbors is $\mathrm{t} \sim 2.7 \mathrm{eV}$, while to the second neighbors is estimated to be $0.02 \mathrm{t}<\mathrm{t}^{\prime}<0.2 \mathrm{t}$.

\subsubsection{Graphene Synthesis}

Graphene synthesis is a demanding process, especially when a large area is desirable, involving either bottom-up (from atoms to nano) or top-down (from bulk to nano) methodologies [8,19]. The bottom-up methodologies include growth on SiC and on metals by precipitation, molecular beam epitaxy and chemical vapor deposition. The top-down methodologies include dry and/or liquid-phase exfoliation, unzipping of nanotubes and chemical exfoliation (Figure 2).

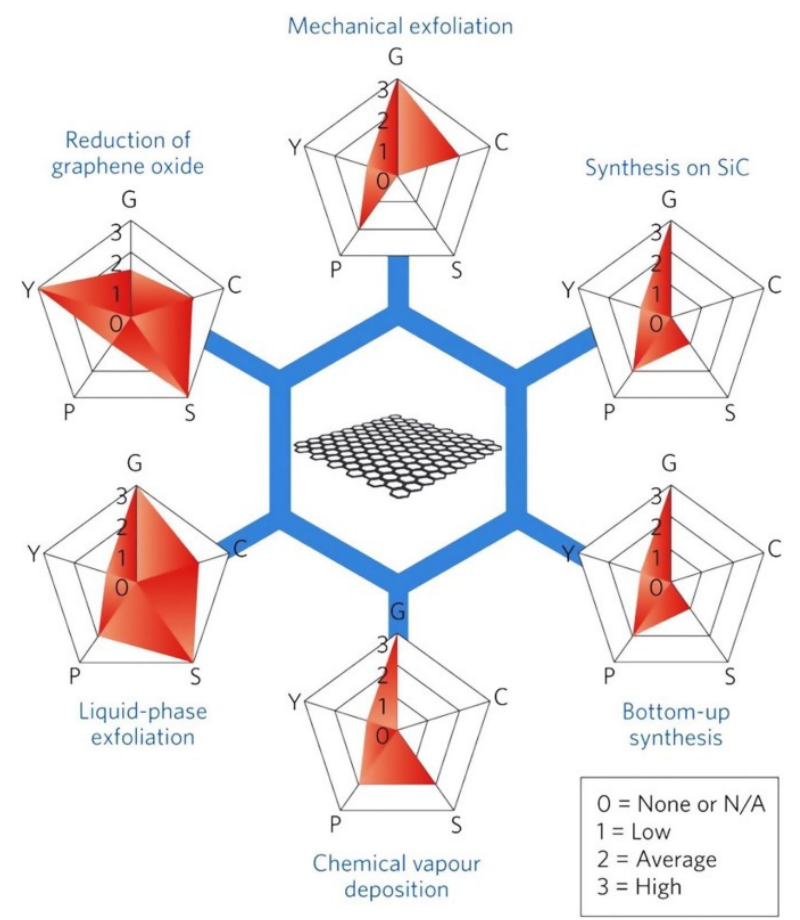

Figure 2. Graphene's common production methods in a scale of $0-3$. G refers to quality, $\mathrm{S}$ to scalability, $\mathrm{P}$ to purity, $\mathrm{Y}$ to yield of each route, and $\mathrm{C}$ to production cost (low value $\Leftrightarrow$ high cost).

Epitaxial growth by chemical vapor deposition (CVD) is perhaps the most known bottom-up methodology, while the oxidation of graphite followed by oxygen reduction and exfoliation is representative of the top-down methodologies. The Scotch-tape method, used by Geim and Novoselov, isolate the graphene layers mechanically. Mechanical cleavage is simple and reliable, as the attractive van der Waals forces are weak, producing graphene 
crystals of ultra high quality, but it is hard to control the layers' quantity and dimensions. The tape's residue is another major obstacle, and it seems impossible to scale-up the process.

The CVD method (plasma-enhanced, thermal, hot/cold wall and other) is used for the synthesis of single or few-layered graphene [37]. Although the synthesis of graphite through heterogeneous catalysis onto transition metals was already known [38,39], the first graphene synthesis by CVD was performed by Somani who used camphor and nickel substrate in 2006 [40]. Since then, the technical improvements were many and nowadays the efforts are focused on the controllable reproduction of n-layered graphene ( $n=$ integer) without impurities and defects. The whole process take place in five broad steps: (a) pre-heat of substrate and precursors, (b) annealing of the substrate without sublimation, (c) insertion of gases/precursors and formation of graphene layer(s), (d) gradual cooling and (e) insertion of inert gases to withdraw the by-products [41].

CVD is a poly-parametric process involving the carbon source, the type of the substrate, the auxiliary gases and the dynamic temperature-pressure relationships [31]. Hydrogen is used for the substrate's annealing and as a precursor under the proper ratio with the carbon source. The carbon source is a gaseous carbohydrate $\left(\mathrm{C}_{\mathrm{x}} \mathrm{H}_{\mathrm{y}}\right)$, usually methane $\left(\mathrm{CH}_{4}\right)$ or ethylene $\left(\mathrm{C}_{2} \mathrm{H}_{4}\right)$ or acetylene $\left(\mathrm{C}_{2} \mathrm{H}_{2}\right)$, but also liquid precursors have been used (pentane and hexane); and the required energy for dehydrogenation $\left(<1200{ }^{\circ} \mathrm{C}\right)$ depends on the carbohydrate's bonds. This energy reduces when the metallic substrate acts as catalyst, i.e., nickel and copper which are the common substrates. The graphene properties, like morphology and layers, result from the type of the substrate and the sequential degree of carbon diffusion. For example, carbon cannot diffuse into the copper; therefore, a graphene mono-layer is formed to the substrate's surface. On the other hand, carbon diffuses into the nickel and the formation of multi-layered graphene takes place during the cooling-step through precipitation (Figure 3). The total and partial pressure of the reactants is also a determinant. High vacuum is necessary during annealing $\left(10^{-4}-10^{-6}\right.$ Torr $)$ to remove any impurities and reduce the roughness, but low pressures (0.1-1 Torr) are suggested during the graphene formation. Similarly, high temperatures smooth the substrate during the annealing and favor the $\mathrm{C}-\mathrm{H}$ bond break but should not exceed the surface sublime point during the graphene synthesis. The cooling rate regulates the layers formation and inhibits the substrate's oxidation and graphene's doping.

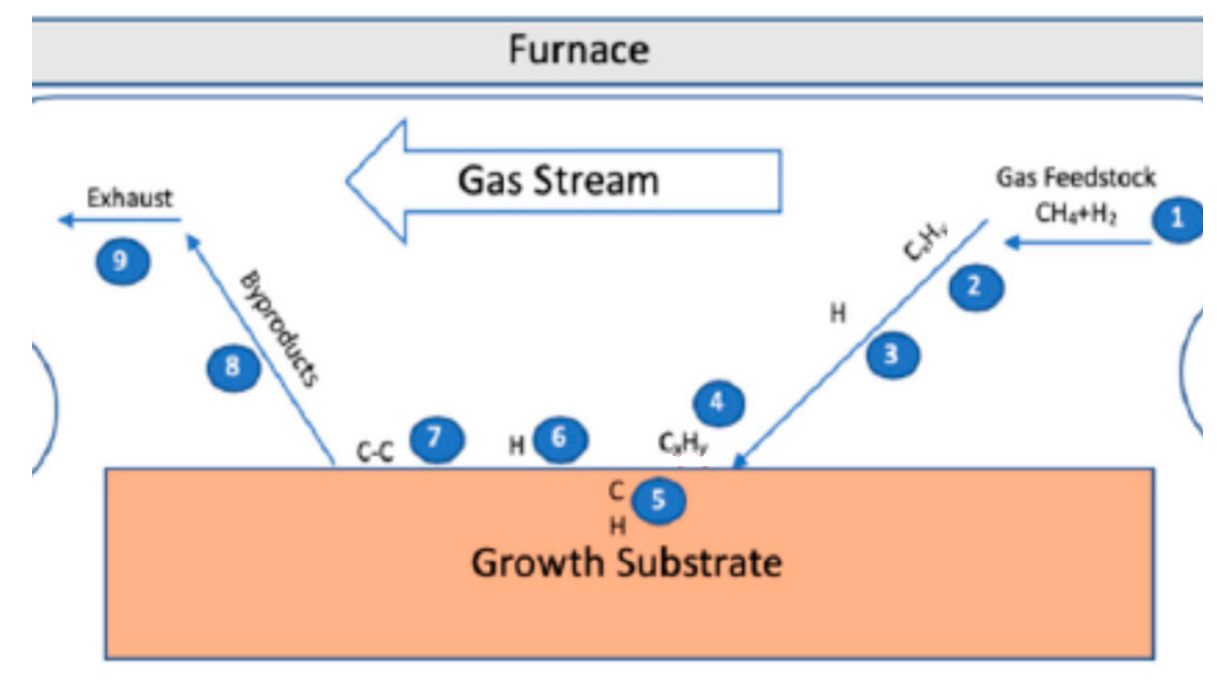

\section{Furnace}

Figure 3. Thermal CVD growth of graphene [44].

Concluding this poly-parametric description, the successful formation of single-layer graphene is followed by the graphene transfer onto a desirable substrate without any 
copper/nickel residues or defects. The liquid-phase transfer involves spin-coating of a polymer, such as PMMA, onto the graphene and etching of the catalyst into a solution, such as ammonium persulfate and acetic acid. This route is time consuming, the metallic traces pollute the environment, and the catalyst is not reusable. The solid-phase transfer involves polymers with low surface tension, such as PDMS and PVA, and graphene detachment and deposition through roll-to-roll (RTR) techniques [42]. Bae et al. have attempted the production of a 30' 'graphene film and nowadays large single-layered graphenes are synthesized to pioneer laboratories [43]. Nowadays, more than 200,000 $\mathrm{m}^{2}$ of CVD graphene film are produced annually.

\section{Graphene Oxide (GO)}

\subsection{GO Synthesis}

The common top-down methodology for graphene production is accomplished with the oxidation of graphite, and then its exfoliation and reduction. The chemical introduction of oxygen groups to graphite results in an expanded interlayer distance and subsequently the chemical or thermal reduction (and exfoliation) to graphene. The produced graphene is actually a reduced graphene oxide $(\mathrm{rGO})$ due to plenty of defects and oxygen residues and is debatable if it can be classified as graphene. It is worth mentioning that chemically reduced GO has structural differences from the thermally processed GO. In addition, trace levels of impurities from the natural graphite $(\mathrm{Fe}, \mathrm{Co}, \mathrm{Ni})$ might dominate the catalytic properties and influence the oxygen reduction process.

Chemists, physicists and materials scientists have been extensively studied GO over the last decade. Each carbon grid is decorated on both sites with covalently attached hydroxyl, epoxy, carboxyl and carbonyl groups, which make it negatively charged and dispersible to several organic solutions. Monodisperse compounds are not feasible since the $\mathrm{sp}^{3}$ carbons are chiral centres. GO is highly dispersible in polar liquids, such as water, ethanol, acetone and acetic acid, and this property facilitates its use in downstream applications [45]. The hydroxyl and epoxy groups decorate the basal plane with a typical ratio of 2:1, while the carboxyl and carbonyl groups, which often dominate the whole GO chemistry, are located to the edges of the flakes and to defect sites. Modification of GO can be done through all these functional groups while its mass production (tones per year) makes it attractive for industrial application.

The first oxidation of graphite was reported by Brodie in Annales de Chimie in 1855 [46]. However, it was Schafhäeutl who first performed intercalation of graphite in 1840 [47]. Staudenmaier presented a less tricky and dangerous methodology for GO formation in 1898 [48], but it was Hummers and Offeman in 1958 who synthesized GO in such a way that adopted by the community and is widely used nowadays (Figure 4) [49]. Actually, the term Charpy-Hummers model would be more accurate as Charpy reported a similar methodology 50 years earlier [50]. The advantages and drawbacks of the three strategies were analyzed by Boehm and Scholz who concluded that the higher $\mathrm{O} / \mathrm{C}$ ratio is feasible with the Hummers method (carbon content $~ 47 \%$ ) [51]. They also showed that the deflagration point of $\mathrm{GO}_{\text {Hummers }}$ is lower than the $\mathrm{GO}_{\text {Staudenmaier }}$ and $\mathrm{GO}_{\text {Brodie }}$. A general rule defines that impurities result in a lower deflagration point. The first thermogravimetric analysis (TGA) was performed by Matuyama in 1954 [52]. 


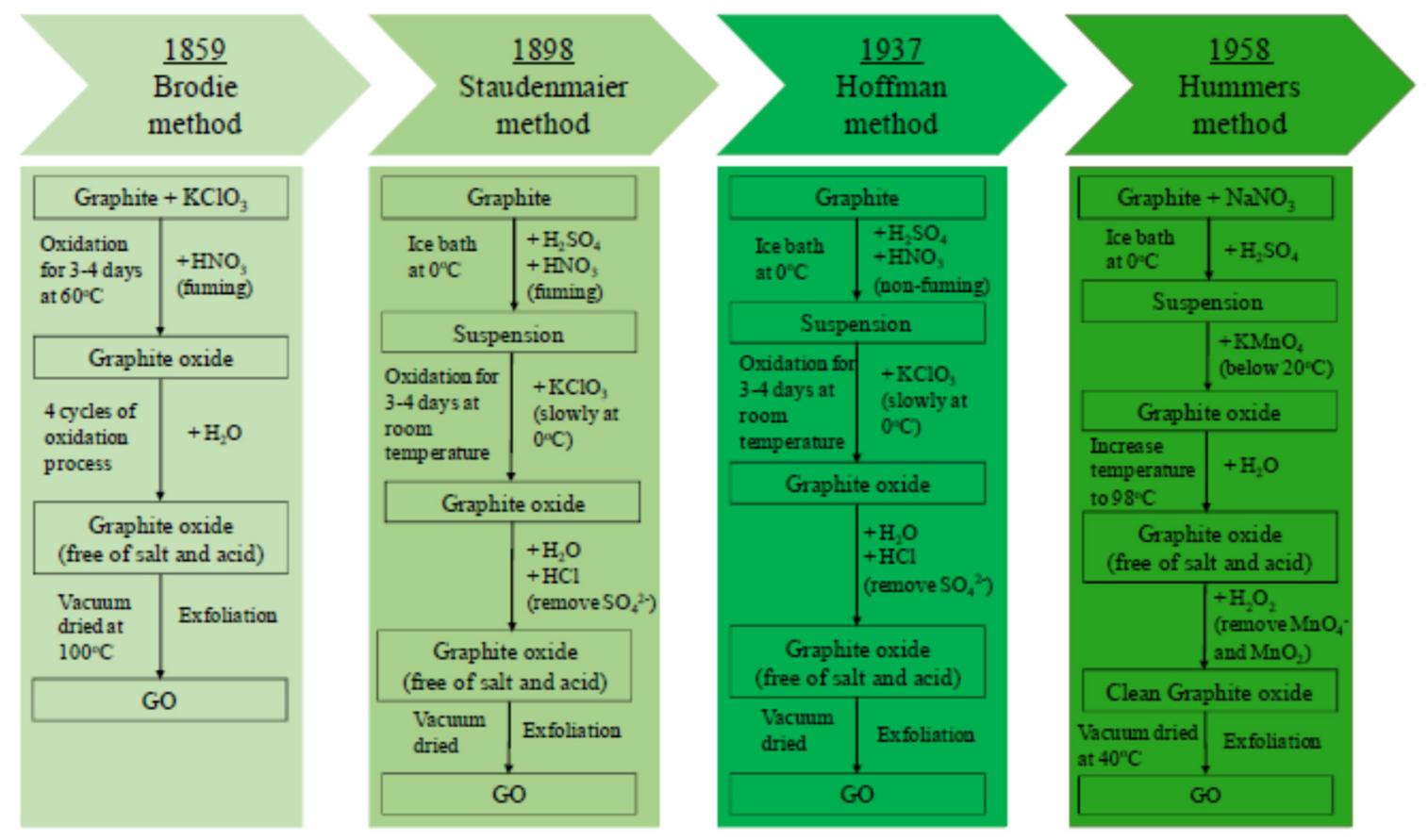

Figure 4. Synthesis routes of GO [53].

The researchers have modified the primary oxidation methods in order to improve the yielded GO (oxidation degree) and/or to speed up the process. A popular modification of Hummers method developed by Marcano et al. requires $\mathrm{H}_{2} \mathrm{SO}_{4}, \mathrm{KMnO}_{4}, \mathrm{H}_{2} \mathrm{O}$ and $\mathrm{H}_{2} \mathrm{O}_{2}$ for GO formation, where sulfuric acid is the concentrated acidic medium that intercalates the graphite and expands it up to 300 times, and potassium permanganate, which is stronger than potassium chlorate, is the oxidant (as $\mathrm{Mn}_{2} \mathrm{O}_{7}$ and/or $\mathrm{MnO}_{3}{ }^{+}$) [54]. Generally, there are four combinations of reactants, $\mathrm{KClO}_{3} / \mathrm{HNO}_{3}, \mathrm{KClO}_{3} / \mathrm{H}_{2} \mathrm{SO}_{4}, \mathrm{KMnO}_{4} / \mathrm{H}_{2} \mathrm{SO}_{4}$ and the more recent $\mathrm{K}_{2} \mathrm{FeO}_{4} / \mathrm{HClO}_{4}$, which might be supported by others such as phosphoric acid. Graphite is oxidized in water-free conditions and then is exposed to water and hydrogen peroxide to terminate the process. Manganese heptoxide is dangerous as it explodes at temperatures above $90^{\circ} \mathrm{C}$, and is formed through the following reaction:

$$
2 \mathrm{MnO}_{4}^{-}+2 \mathrm{H}^{+} \rightarrow \mathrm{Mn}_{2} \mathrm{O}_{7}+\mathrm{H}_{2} \mathrm{O}
$$

$\mathrm{HMnO}_{4}, \mathrm{Mn}^{2+}, \mathrm{H}^{+}, \mathrm{SO}_{4}{ }^{2-}$, and $\mathrm{K}^{+}$are the byproducts from quenching. The removal of ions requires washes with $\sim 1: 10 \mathrm{HCl}$ aqueous solution. In a typical $\mathrm{GO}$, the $\mathrm{sp}^{3}$ carbon atoms are more than the $\mathrm{sp}^{2}$ hybridized. When the carbon content is below $55 \%$, which corresponds to a $\mathrm{C} / \mathrm{O}$ ratio below 2.5, it is indicative of graphite's over-oxidation, which is a process that might degrade/rupture the carbon framework liberating $\mathrm{CO}_{2}$. Care should be taken during the GO drying. The presence of potassium ions (if any) increases the flammability, while vacuum freeze-drying seems to be the most suitable technique for the solvent water removal. However, freeze-drying might enhance GO partial restacking and spray-drying is an alternative. Unavoidably, all solid/powder GO samples contain more or less intercalated water $[35,55,56]$

The exact chemical structure of GO cannot be specified due to the irregular density of the defects and the oxygen groups. Various models have been proposed since 1930 (Thiele) [57] and several authors have classified GO to amorphous materials, but the model proposed by Lerf-Klinowski (1998) is widely acceptable (Figure 5) [58]. They describe GO as a 2-domain layer where graphene areas are randomly distributed to the oxidized plane. The oxidized plane is heavily decorated with hydroxyl and epoxy groups, while carboxyls and carbonyls terminate the edges and the defects/holes. The popularity of this model was raised by the confirmation of the 2-domain layer, with the assistance of nuclear magnetic 
resonance (NMR) spectroscopy; and indeed the graphene areas are like isolated islands onto the oxidized plane which constitutes more than $70 \%$ of the flake. GO is considered as a non-stoichiometric metastable carbon compound with more than $2-3 \%$ defects that liberates $\mathrm{CO}_{2}$ at temperatures as low as $45^{\circ} \mathrm{C}$ [59]. Moreover, variations in oxidation degree might present to the flakes of the same batch and the size of the $\mathrm{sp}^{2}$ domains increases with time [34,55].
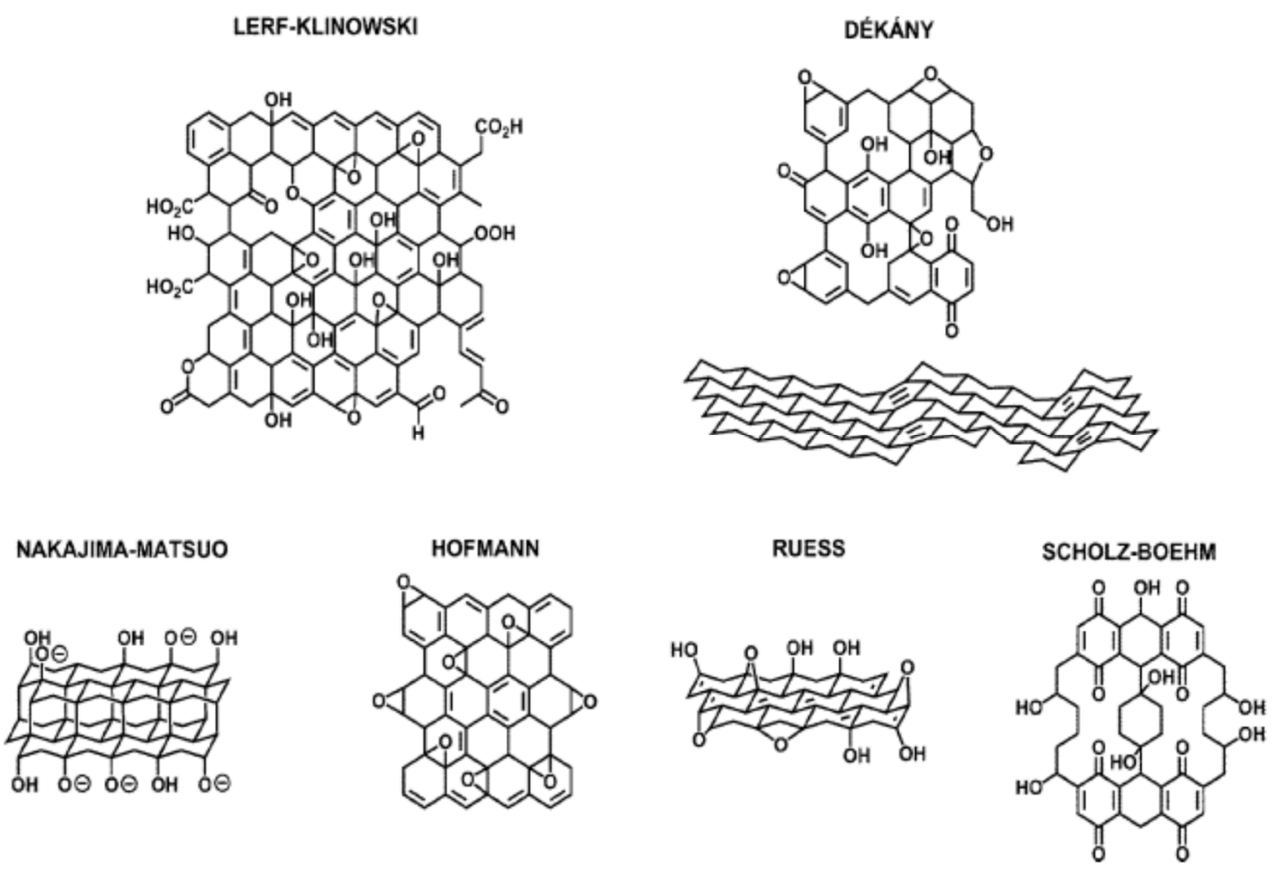

Figure 5. The proposed structural models of GO [60].

The resulted acidity of GO solutions is better interpreted by the Dimiev-Tour (DT) structural model, where diols are formed after the reaction of $\mathrm{MnO}_{4}{ }^{-}$with the peripheral isolated double bonds of carbon atoms, and the subsequent breaking of C-C bonds results in ketones formation. GO solutions have typical $\mathrm{pH}$ from 2.0 to 4.5 (often described as Lewis acid), but, when the flakes are separated from the solution, the $\mathrm{pH}$ turns neutral [45]. Thus, the hydronium cations are strictly associated with GO and cannot diffuse to the water. On the other hand, acidity can be induced after the partial degradation of the $\sigma$-framework. Typically, GO contains one acidic site every 6-8 carbon atoms and the carboxyls in LK model cannot support such a high acidity. On the other hand, phenols (ketones and enols) are functional groups that present acidic character and are formed from the decomposition of the tertiary alcohols after the nucleophilic attack by water molecules. Further transformation of enols to other groups, probably to ketons, is possible when GO is dried. The divalent nature of oxygen and the formation of carbonyls are responsible for the $\mathrm{C}-\mathrm{C}$ cleavage and the generation of holes. The removal of one carbon atom from the basal plane results in three new edge atoms; thus, the removal of two or more neighboring carbon atoms generate space for the formation of in-plane carboxyls and other functional groups. On the other hand, if a carboxylic acid is formed into a small vacancy, the neighboring carbons may become sterically hindered; therefore, the carboxylic acids are plausibly located to the flake edges. A thorough understanding of both the chemical structure and the mechanism of GO formation is critical for developing functionalization protocols and low-cost products with targeted properties. For example, the oxidants/chemical compounds are known in the Hummers method, but the actual oxidizing agents/species that interact with the graphite are not. Furthermore, it is known that the rate-determining step in GO formation is the diffusion of the oxidant, but the reason that graphitic domains survive from the oxidizing agent remains unanswered. On the other hand, it is known that epoxides, which are the first-formed functional groups on graphite, 
convert to organic sulfate and then, after the reaction with water, they further convert to tertiary alcohols, but the over-oxidation might rearrange the grid with pentagons and other structures. Classical organic chemistry reactions occur differently with GO functional groups since their proximity promotes their conjugation and cross-self-protection [55].

\subsection{GO Properties}

GO behave like an insulator with sheet resistance $R_{s} \sim 10^{12} \Omega$ /sq due to defects and oxygen groups that isolate the $\mathrm{sp}^{2}$ areas, but a reduced GO (rGO) could present 3-9 times higher conductivity due to the decreased amount of oxygen groups and the restoration of the honeycomb network. Conductivity of $1314 \mathrm{~S} / \mathrm{cm}$ and C/O ratio of 246:1 has been reported for $\mathrm{rGO}$, while $5 \%$ of oxygen presence reduces the thermal conductivity $\sim 90 \%$. A theoretical specific surface area of $\sim 890 \mathrm{~m}^{2} / \mathrm{g}$ has been calculated for GO and a Young's modulus of $\sim 250 \mathrm{GPa}$. The typical thermal conductivity of GO is around $3 \mathrm{~W} / \mathrm{m} \cdot \mathrm{K}$ and the $\mathrm{C} / \mathrm{O}$ ratio from 2:1 to 3:1, while that of rGO from 4:1 to 12:1 [61-63]. Paradoxically, surface areas of $\sim 3000 \mathrm{~m}^{2} / \mathrm{g}$ have been reported for rGOs treated with $\mathrm{KOH}$ and microwaveexfoliation as a result of heptagon and octagon patches to the network [55].

GO has superb photoluminescence properties, making it excellent for bio-sensing and photoelectronics. GO is used in fluorescence imaging, both in vitro and in vivo, due to its ability to photoluminescence in the near infrared (NIR) in combination with the natural transparency of biological tissues in that spectral region. It can also be used in composites, sorption materials, drug/gene delivery and energy storage. Hybrid GO fibers find application in supercapacitors, aerogels, stretchable conductors, biomarkers and functional fabrics $[36,62,64-66]$. GO thin films can be easily produced either by filtration or drop casting, and form membranes which present high permeability to water molecules and impermeability to other molecules and even atoms such as nitrogen and oxygen. Tuned GO with a bandgap range from 1.7 to $2.1 \mathrm{eV}$ has been used in field-effect transistors (FET) utilizing its p-type semiconducting behavior [55].

The optical properties of GO, including absorbance and photoluminescence, are alterable through its bandgap modification. Electronic transitions in GO are revealed in the range of ultraviolet to visible. The two characteristic absorptions in GO occur at $\sim 230 \mathrm{~nm}$ and $\sim 300 \mathrm{~nm}$, where the former results from the $\pi \rightarrow \pi^{*}$ transitions in the aromatic $\mathrm{C}=\mathrm{C}$ bonds and the latter, which is less energetic, from the $\mathrm{n} \rightarrow \pi^{*}$ transitions in the $\mathrm{C}=\mathrm{O}$ bonds [56]. The p orbitals could be in-phase or out-of-phase allowing combined transitions between the low-energy $\pi$ orbital and the high-energy $\pi^{*}$ (Figure 6 ). In the case of rGO, the absorption from $n \rightarrow \pi^{*}$ transitions exhibits decreased intensity followed by spectrum broadening due to the less carbonyls, and increased absorption in the visible appears. If the $\mathrm{GO}$ reduction leads to restoration of the $\mathrm{sp}^{2}$ network, then the intensity of the $\mathrm{C}=\mathrm{C}$ peak appears increased.

Photoluminescence is the excitation/emission process over a certain bandgap of the functionalized graphene. An electron absorbing an incoming photon and jumping to higher orbital leaves behind a positively charged hole. This electron-hole pair is called an exciton. Intrinsically, the electron is transferred to the LUMO (lowest unoccupied molecular orbital) and the hole to the HOMO (highest occupied molecular orbital). After a short time period, the exciton reunites and a photon with lower energy than the incoming is emitted. The ratio of the absorbed to emitted photon is called fluorescence quantum yield. The reported quantum yields for GO are between $0.02-0.5 \%$. The fluorescence lifetimes in GO last from picoseconds (for the red emission) to nanoseconds (for the blue emission). In general terms, the $\pi \rightarrow \pi^{*}$ gaps are on the order of $0.3-4.0 \mathrm{eV}$ [55].

GO is highly permeable to cell membranes and shows low toxicity both in vivo and in cellular assays. However, GO cytotoxicity measurements are not reliable for MTT-based assays. Its negative charge, due to the many oxygen functionalities, and the low-molecularweight impurities, residuals from the synthesis/purification, induce toxicity, but this factor is quite controllable through modification with polymers, dendrimers, etc. Interestingly, GO shows moderate cytotoxicity at low concentrations $(<10 \mu \mathrm{g} / \mathrm{mL})$, but, at higher doses, 
the toxicity depends on its size, charge and aggregation state. Moreover, the biological fluids have an impact on GO toxicity as their proteins interact/bind with GO and modulate its properties. The latter is a crucial parameter in GO-based targeted therapy, such as cancer therapy, where specific drugs, proteins and nucleic acids are loaded on the basal plane. GO shows high permeability and retention effect (EPR effect) in various cancer cell tumors, while its property to absorb light in the NIR range heats up the system and causes the cell death through hyperthermia [8]. Although hemoglobin and water of the healthy neighboring tissues can absorb in NIR, when the radiation is between 700-980 nm (first biological window) as well as 1000-1400 nm (second biological window), the light triggers/heats the GO platform only. Such light can travel several centimeters from the skin to human tissue, while optical fibers are used for deeper located tumors. It has been reported that highly efficiently nano-GOs (less than $300 \mathrm{~nm}$ in size) absorb at 808 and $1200 \mathrm{~nm}$. Moreover, GO can be functionalized with folic acid (FA) which acts as ligand which binds to cancer cells that over-express the FA receptor. This non-invasive targeted therapy, namely photothermal therapy (PTT), is highly attractive nowadays as it reduces the side effects of chemotherapy, while, when these two therapies are combined, they exhibit synergistic effects [55].

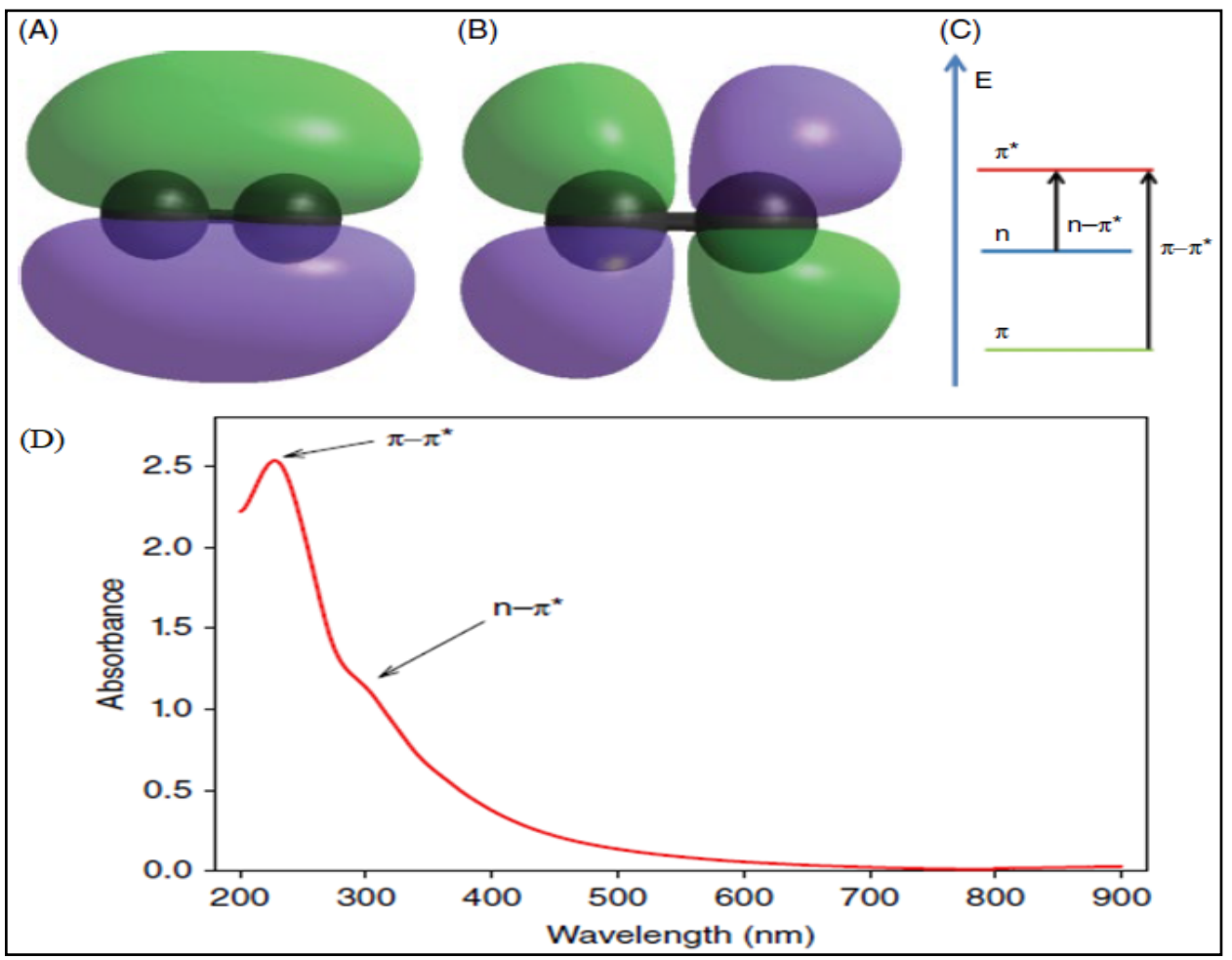

Figure 6. The in-phase and out-of-phase carbon p orbitals $(\mathbf{A}, \mathbf{B})$, the energy diagram and transitions between $n, \pi$ and $\pi^{*}$ orbitals (C), and a typical UV-Vis absorption spectrum of GO (D) [55].

Synthesis of GO membranes is a recent trend that applies to gas-selective permeability and to water purification $[64,67]$. So far, the membranes were based to polymeric compounds due to the ease of formation and modulation, low-cost and mass production. However, the lack of tradeoff between permeability-selectivity leads to the production of novel, hybrid or not, membranes where both parameters show high-high statistics. In general terms, the flux of a membrane is inversely proportional to its thickness; thus, monolayer graphene-based membranes have emerged as a hot spot. An intact single layer graphene is impermeable to gases and ions due to its high electron density and efforts to generate ordered sub-nanometer pores by ion-beam irradiation are on the go. On the other hand, an engineered GO with high purity, orientated porosity and specific pore width constitutes a good candidate for membrane material [55]. 
The first report of water-permeable GO membrane was published by Boehm et al. in 1961 [68], and a nanometer-thick film was synthesized by Japanese scientists 30 years later. An anhydrous GO membrane with thickness 500 nm that was synthesized by Geim's group in 2012 showed fast permeation of water molecules but complete impermeability to other liquids and gases [69]. The water permeability was interpreted by the hydrophilic nature of GO and the subsequent interlayer opening. The unorganized dispersion of the functional groups on the GO layers affects the diffusion of the molecules and ions, while the irregular presence of defects $(\sim 2 \%)$ generates geometrical pathways different from the conventional/simplified slit-cylindrical-spherical as well as steric hindrances. Nowadays, it is well known that the transport properties are also affected by the GO size and stacking manner, the degree of oxidation, and the amount of the intercalated water. Generally, the gas permeability follows the kinetic diameter $\left(\mathrm{He}>\mathrm{H}_{2}>\mathrm{CO}_{2}>\mathrm{O}_{2}>\mathrm{N}_{2}>\mathrm{CH}_{4}\right)$. A very important parameter for gas diffusion is the feed to permeation pressure ratio, which must be higher than the potential resistance inside the GO pores [55].

Regarding the water transportation in GO membranes, the oxygen groups in the hydrophilic domains interact with the water molecules strongly and impede their momentum, while the hydrophobic $\mathrm{sp}^{2}$ patches accelerate them. The water flux has a pressuredependent character but not a linear one. The water molecules are actually trapped between the GO layers and form water-pockets under an applied pressure. As the pressure increases, the shape of the pockets converts from round to flattened rectangle and the cross-sectional area increases allowing higher permeation, whilst the further pressure increment results in round ripples and shrinkage of the path. Consequently, the rejection rate is increased due to the reduced cross-sectional area. After the pressure release, the compressed nano-channels retrieve their original state as the stored strain energy surpasses the van der Waals forces around the provisional contact region.

\subsection{GO Composites}

Broadly speaking, polymers are lightweight, chemically resistant, and easy to manufacture materials with molecularly tunable and controllable properties. Their combination with other materials is the centre of attention for chemists and materials scientists, who aim to develop hybrids that preserve the advantages of the matrices. The main purpose of using GO to such composites is to increase the mechanical properties, but its hydrophilic nature makes it incompatible with organic polymers. Thus, the surface functionalization of GO is a generic feature, with aliphatic amines being top-candidates for tailoring its properties. On the other hand, the oxygen groups, especially the carboxyls, charge the GO thin films negatively, and layer-by-layer composites can be formed via electrostatic interactions with positively charged polymeric substrates [55].

Polymers could be soft, elastic, hard and/or brittle. The core principle of a GO reinforced matrix is the load transfer from the polymeric phase to the filler. Ideally, the final composite should be reproducible and its final properties easily predictable. For instance, it is well known that, when a polymer with Young's modulus $~ 5 \mathrm{GPa}$ is well-mixed with $10 \mathrm{vol} \%$ graphene ( 1 TPa), the expected composite's modulus will be 100 GPa. However, hybridizing a polymer with nano-particles should be economical and GO is a cost-effective alternative to graphene and CNTs. Moreover, the optimum loading of GO that maximizes the toughness and stiffness is usually very low, from tenths of $1 \%$ to $5 \%$. Care should be taken to avoid the filler agglomeration, which results in reduced toughness and degradation. Similarly, the weak interfacial energy results in fracture propagation from the filler into the matrix. The rich GO chemistry toward functionalization is also advantageous over other nano-particles. Continuum mechanics and molecular dynamics are employed to predict the behaviour of graphene-based composites [55].

GO, as reported by Hofmann and his colleagues in 1962 [70], can also induce conductive properties to polymers upon chemical or thermal reduction. In general terms, GO should be perfectly dispersed when reinforcing matrices, while a lower homogeneity with interconnected network is more beneficial for electrical applications. GO itself presents 
low conductivity $\left(\sigma_{\mathrm{GO}} \sim 10^{-3} \mathrm{~S} / \mathrm{m}\right.$ ), thus reduction and doping are commonly applied to enhance its electrical properties. Furthermore, the type of the matrix and the subsequent filler-matrix interactions are crucial parameters of the composite's electrical properties. Ideally, parallel assembly of the filler provides anisotropic conductivity (one direction), enhances the filler's efficiency, and improves the composite's total conductivity. It is worth mentioning that, when conductive particles are in a vicinity of less than $10 \mathrm{~nm}$, the electrons hop, and these contact points/bridges, especially if they form series, decrease the conductivity. Thus, if conductivity enhancement is the only demand, a single graphene wire along the polymeric matrix is enough.

The three common routes to synthesize conductive graphene-based composites are: the latex-blending, the polymer-blending, and the aero-blending. The first method involves micro-latex rigid particles dispersed into GO (or rGO) solution where the two phases become one after drying and pressing. The second route, which is perhaps the most intellective, requires two immiscible polymers that form a co-continuous phase where the graphenic sheets are self-deposited to the interface. The third way involves a 3D graphene network produced by CVD using nickel substrate or with freeze-drying in the case of GO, and then the incorporation of the elastomer. The graphene loading could be less than $0.5 \mathrm{wt} \%$ while the resulting conductivity could reach $1000 \mathrm{~S} / \mathrm{m}$ [71].

Several strategies have been developed for composite preparation aiming at the homogenous graphene dispersion into the polymeric matrix. Otherwise, the mechanical reinforcement will be inadequate and a product of low quality. The necessity for fine dispersion and exfoliation dates back to 1915 when Aylsworth used expanded graphite to synthesize polymeric-graphite composites. He faced difficulties due to graphite's high surface energy and inert nature. The two key points for fine dispersion are the aspect ratio of the filler and the nature of the interface between the graphene and the matrix. The solution compounding is a facile and fast technique where the graphene suspension is mixed with a solid or dissolved polymer. Simple or shear mixing and ultrasonication are used to homogenize the suspension and then molding for the solvents' removal. Filler agglomeration, as a result of the van der Waals interactions and its high specific surface area, should be carefully avoided due to the induction of failure points. The in situ polymerization technique describes the mixture of solid graphene with monomers or pre-polymers followed by polymerization. The filler grafts on the polymer, which could be functionalized to enhance the components compatibility. Increased viscosity during polymerization might limit the loading fraction. In addition, the reduction of graphene oxide is possible during the polymerization. The melt mixing is a fast, simple and inexpensive methodology implemented by industries to produce graphene-based thermoplastic nanocomposites. The polymer melts at elevated temperatures and is mixed with powdered graphene into extruders. Although this technique results in poorer dispersion than the aforementioned, it has the potential to induce adequate properties to the composite as well as to scale-up. In conclusion, the layer-by-layer assembly allows for novel functional composites which could be applied to Li-ion batteries, field-effect transistors, supercapacitors and others. In this versatile technique, various nanomaterials are combined to produce multilayer films of specific thickness and hierarchical architecture. This technique is poly-parametric involving $\mathrm{pH}$, temperature, ionic strength, hydrogen and/or covalent bonding and chemistry interactions [35,55].

Micromechanical studies are developed to predict the behaviour of graphene composite materials. Small amounts of the high-modulus graphene can reinforce the low-modulus polymeric matrix significantly, and a typical evaluation method is based on the acquisition of stress-strain curves from tensile tests. The parameters that affect the composite properties are the filler dispersion into the matrix and their interactions, its synthesis method and the orientation. Strong bonding of filler and matrix results in efficient stress transfer. Occasionally, graphene oxide is preferred over graphene platelets due to the presence of functional groups which promote the filler-matrix interactions. Interestingly, graphenes exhibit higher modulus when the matrices possess high Young's modulus (Figure 7). Further studies 
in such behaviours/plots may reveal the reinforcement mechanisms of graphene-based composites. A recent trend is the application of hybrid fillers that consist of graphene and inorganic materials, which aim to utilize the additive or synergistic effect as well as to reduce the product's final cost [35].

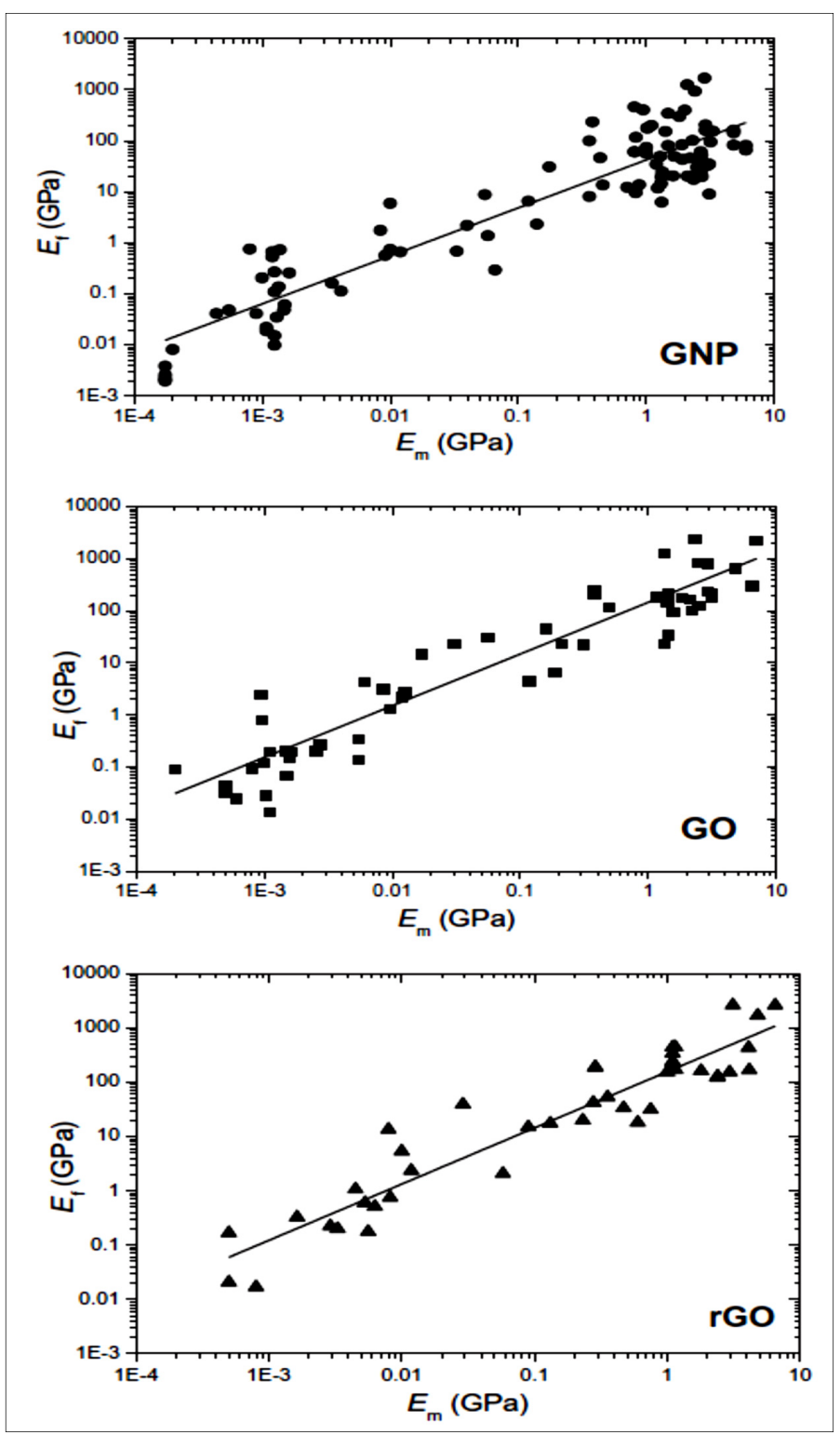

Figure 7. Graphene Young's modulus as a function of the matrix modulus [35].

\subsection{Reduced Graphene Oxide (rGO)}

Reduction is the GO reaction that has the most obvious signs as the solution color turns from yellowish to black due to the restoration of the $\mathrm{sp}^{2}$ network [61]. However, the complete restoration is impossible due to the residual defects from GO synthesis, where the holes are generated from the liberation of carbon dioxide and the successive water washings [59]. On the other hand, the oxygen groups can be reduced more or less effectively [72-74]. Tertiary alcohols and epoxides are cleaved quite easily, but the functionalities at defect points, such as carbonyls, show higher resistance. The chemical reduction of GO is not a recent trend as the first attempt was made by Kohlschütter and Haenni in 1919 [75], and the popular hydrogen sulphide-reduced GO by Hofmann and Frenzel was published in 1934 [76]. Nowadays, sodium borohydride and the combination of hydrogen iodide with acetic acid are used for reducing GO. Interestingly, solvothermal deoxygenation of 
GO occurs in strong bases' solutions of $\mathrm{NaOH}$ and $\mathrm{KOH}$ in mild temperatures $\left(<100^{\circ} \mathrm{C}\right)$. Moreover, sodium hydroxide can also cleave the organosulfate groups of GO. Other popular methods include hydrazine as well as green reductants such as ascorbic acid, alanine and glucose (Figure 6). Evaluation of rGO involves its electrical conductivity $(\sigma)$ and the $\mathrm{C} / \mathrm{O}$ ratio. Generally, if the lattice is not damaged, a C/O ratio around 10 is indicative of good electrical conductivity [30]. Elemental analysis is less accurate as it tends to show higher oxygen content than the real one. Thus, X-ray photoelectron spectroscopy (XPS) is suggested. On the other hand, conductivity of rGO, which is commonly evaluated with four-point-probe measurements, provides higher accuracy, but the experimental process is trickier, mainly due to the film thickness (d) and the substrate that is deposited. An alternative expression of conductivity is resistivity which is expressed as $R_{s}=1 / \sigma \cdot d(\Omega / s q)$.

In general terms, the chemical reduction alone is not enough for production of highly conductive rGO. Increased conductivity is obtainable $(200-300 \mathrm{~S} / \mathrm{cm})$ with reconstruction of the network by annealing at elevated temperatures around $900{ }^{\circ} \mathrm{C}$. However, annealing without chemical reduction generates many defects on the grid due to the liberation of carbon monoxides and dioxides. Such type of rGO is ideal in electrode-form for supercapacitors and batteries due to the increased porosity, which allows easy cross-plane diffusion of ions and the large surface area $[62,77,78]$. The main reduction of functional groups occurs between $160-300{ }^{\circ} \mathrm{C}$, while the carbonyls are cleaved at temperatures above $500{ }^{\circ} \mathrm{C}$. Reconstruction of the network takes place at above $700{ }^{\circ} \mathrm{C}$, and temperatures more than $900{ }^{\circ} \mathrm{C}$ are required for less than $1 \%$ oxygen content. However, complete elimination of hydroxyl and epoxide groups is achievable even at $100^{\circ} \mathrm{C}$ in vacuum. The most conductive rGO has been prepared through photoreduction, while, among the chemical reduction methods, rGO prepared with $\mathrm{HI} / \mathrm{AcOH}$ exhibits the best electrical properties $[79,80]$. The most conductive tpGO has been synthesized by Yang et al. and Wang et al. [81,82]. Broadly speaking, rGO samples with a C/O ratio of up to 5 retain their swelling properties in water. In addition, when the porosity increases to the scale of macro-porosity, the surface area diminishes $[55,83]$.

The thickness of a typical rGO monolayer varies between the thickness of a graphene (0.5-0.6 $)$ and a GO monolayer (0.8-1.2 $\AA$ ) (Figure 8) [84]. Typically, an increase in rGO thickness leads to higher conductivity and lower transparency, and, with the suitable tradeoff, the rGO films have the potential to decrease the cost in many products such as liquid crystal displays (LCDs), touch panels, organic light emitting diodes (OLEDs), and even replace the expensive indium tin oxide (ITO) in solar cell panels. Indium is a rare element, while ITO-based electrodes are brittle, incompatible with strong acids, and unstable at high temperatures. An extra advantage of graphene-based electrodes in photovoltaic systems that results in higher efficiency is the increased electron collection through their ability to absorb in a wider spectrum $[35,55]$.

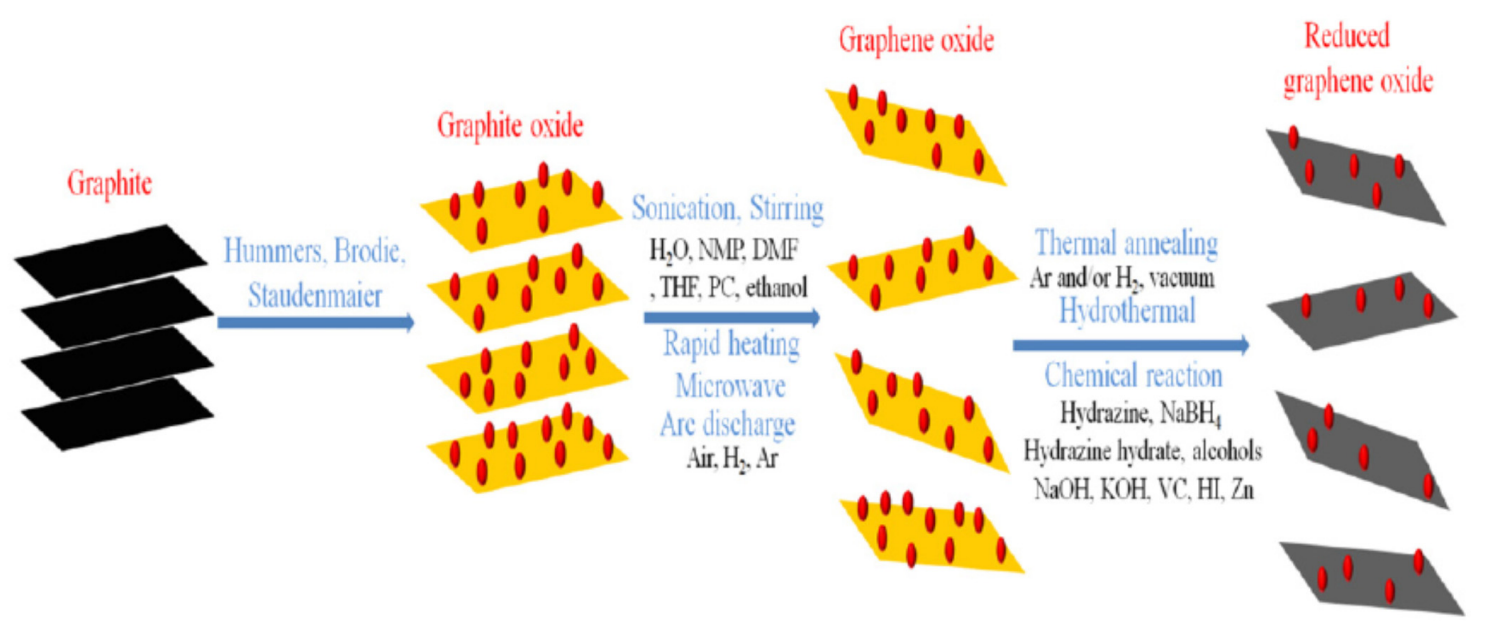

Figure 8. Synthesis of rGO from pristine graphite [84]. 


\section{Characterization Techniques}

3.1. X-ray Diffraction (XRD)

X-rays, discovered by Roentgen in 1895, are a form of electromagnetic radiation with wavelengths less than $3 \AA$. X-rays are highly energetic ionizing radiation produced by the scattered electrons that are impinged on the matter, and their diffraction is a tool for investigating the atomic structure of the specimen [85]. Interference patterns are produced when a monochromatic X-ray hits the sample's crystal lattice. The use of monochromatic radiation is preferred due to the high intensity and the ideal generation of characteristic lines. The characteristic radiation, termed $\mathrm{K} \alpha$, results from the replacement of $\mathrm{K}$ shell electrons by $\mathrm{L}$ shell electrons to the metal target. The most commonly used target is copper and the produced $\mathrm{CuK} \alpha$ radiation has wavelength $\lambda=1.54 \AA$. Alternative metallic targets/radiations are the $\mathrm{CrK} \alpha$ with $\lambda=2.28 \AA$, FeK $\alpha$ with $\lambda=1.94 \AA$, and $\mathrm{MoK} \alpha$ with $\lambda=0.71 \AA$. X-ray diffraction occurs when the radiation is scattered by the atoms of the specimen which reemit $X$-rays of the same wavelength as the incident radiation. The scattered X-rays could be in-phase with the sample's atomic spacings or out of phase. The in-phase X-rays interfere constructively and emerge from the crystal as intense/diffracted beams. The collimators and the receiving slit reduce the noise and the spread of the beam, and increase the resolution by reducing the unwanted radiation, such as $K \beta$ by $\mathrm{M}$ shell electrons. Subtraction of the parasitic background caused by factors, such as the apparatus, the thermal agitation of the atoms and the air, is necessary [86]. Crystallinity is quantified by measuring the diffraction of the $\mathrm{X}$-rays from the planes of the atoms within the specimen. The diffractogram presents the relative intensity of the diffracted X-rays as a function of the scanning angle $2 \theta$, which is the actual angular deviation from the incident beam. Diffraction occurs from planes in those crystallites that are coplanar with the focal plane and fulfill the Bragg condition (Equation (3)). Crystalline substances present discrete characteristic peaks in their diffraction patterns:

$$
\mathrm{n} \cdot \lambda=2 \mathrm{~d} \cdot \sin \theta
$$

where $\mathrm{n}$ is an integer, $\lambda$ is the radiation wavelength, $\mathrm{d}$ is the distance between a given set of planes in the atomic lattice of the sample, and $\theta$ is the diffraction angle in degrees. Thus, for a given wavelength of radiation and constant interlayer distance, the diffraction will occur at a unique angle. The dominant peak of graphite is located at $2 \theta \approx 26^{\circ}$ while that of $\mathrm{GO}$ at $2 \theta \approx 10^{\circ}$. Occasionally, depending on the synthesis route, a secondary peak at $2 \theta \approx 43^{\circ}$ is visible [87-91].

\subsection{Scanning Electron Microscopy-Energy Dispersive X-ray Spectroscopy (SEM-EDS)}

The morphology of a large specimen can be quickly scanned/visualized by electron microscopy, thus SEM is broadly used in daily routine analysis [34]. A tungsten filament (cathode) emits thermionic electrons which are accelerated across a potential difference $(1.0-30.0 \mathrm{kV})$ towards the anode. The beam is aligned to the sample through condenser and objective electromagnetic lenses under vacuum $\left(<10^{-5} \mathrm{~Pa}\right)$. Secondary and backscattered electrons as well as Auger electrons and X-rays are emitted during the scan, and their interaction with the detectors sends signals to the software which converts them to grayscale images. Secondary and back-scattered electron detectors deliver images of the specimen while the X-ray spectrometer provides information about the chemical composition $[92,93]$. Secondary electrons are mainly outer shell electrons produced by inelastic scattering while the backscattered electrons result from large angle elastic scattering between the sample and the incident electrons. Care should be taken for soft samples, such as polymers, to avoid surface and structural damages from the beam. Samples that are not conductive require pretreatment of their surface. Usually, a gold or carbon overlayer is sputter-coated to the specimen. The whole process involves Argon gas, ultra high vacuum and a gold/carbon target, and lasts a few minutes. A strong potential difference ionizes the Argon gas, and the ions are accelerated to the target, thus releasing atoms from the 
target. These atoms travel and coat the substrate, allowing a detailed visualization. The typical graphite flakes have shiny squamous structure while GO presents wrinkles due to the oxidation process $[87,90,94]$.

\subsection{Fourier Transform Infrared Spectroscopy (FTIR)}

Infrared spectroscopy is a qualitative characterization technique; however, it occasionally is used quantitatively when other more suitable methods, such as ultraviolet or nuclear magnetic resonance spectroscopy, are not applicable. Infrared radiation ranges on the right of visible till the microwaves, from $0.75-1000 \mu \mathrm{m}$, being subdivided to the (i) near infrared $(0.75-2.5 \mu \mathrm{m})$, (ii) middle infrared $(2.5-25 \mu \mathrm{m})$ and (iii) far infrared $(25-1000 \mu \mathrm{m})$. The wavelength $(\mu \mathrm{m})$ is converted to frequency $\left(\mathrm{cm}^{-1}\right)$ for characterization purposes. When a molecule absorbs infrared radiation, the flipping dipole changes, and the intensity of the peaks in the spectrum depend on these changes. However, a specific vibration frequency might correspond to more than one molecule, while vibrations that slightly differ (less than $1 \mathrm{~cm}^{-1}$ ) might overlap.

Vibrations could be symmetric or asymmetric, and are categorized as stretching $(v)$ and bending $(\delta)$. Stretching vibrations are characterized by a continuous distance change along the bond axis, while the bending by angle changes between two bonds. Scissoring, rocking, wagging and twisting are the four types of the bending vibrations. The deformation of the first two occurs 'in plane' while the other is 'out of plane'. A molecule of more than two atoms could present all the aforementioned vibrations.

The common FTIR sampling techniques are the transmission mode with the use of $\mathrm{KBr}$ pellet and the attenuated total reflection (ATR). The configuration of the latter simplifies the characterization of the sample as it allows direct measurements without the need for sample preparation, which might affect both the sample and spectra, and lasts just a few minutes. Moreover, the penetration depth of the beam $(\sim 2 \mu \mathrm{m})$ provides reliable information for the entire specimen under a small pressure of less than $100 \mathrm{~N}$. Different approaches are applied due to the form of the sample (powder, film, wax and liquid) and the tip geometry (flat, conical, spherical). However, all measurements start with recording the background spectra which results from the cleaned crystal surface [95].The common crystal plates consist of diamond, zinc selenide $(\mathrm{ZnSe})$ or germanium $(\mathrm{Ge})$. The crystal must possess a greater index of refraction than that of the sample. The refractive index of Ge is $\sim 4.0$ while that of diamond and ZnSe 2.4 [96]. In addition, the IR light angle of incidence must be small enough to reflect totally and avoid transmittance into the sample. The absorption spectrum occurs from an evanescent wave that partially penetrates the sample. The reflected beam conveys information characteristic of the absorbing molecules [97]. Ge crystal is brittle and used for highly absorbing materials, diamond for rigid or caustic samples and ZnSe for viscoelastic samples [98-100]. Although ZnSe is relatively inexpensive, it is soft and tends to scratch so a thin diamond layer is commonly laminated over the ZnSe crystal for protection. Similarly, $\mathrm{ZnSe}$ is used as support element to diamond crystals to reduce the cost [101]. The characteristic peak of graphite is located at $\sim 1557 \mathrm{~cm}^{-1}(\mathrm{C}=\mathrm{C})$. GO hydroxyls $(\mathrm{O}-\mathrm{H})$ appear $\sim 3400 \mathrm{~cm}^{-1}$, the carbonyl groups $(\mathrm{C}=\mathrm{O})$ are located at $\sim 1730 \mathrm{~cm}^{-1}$, the carboxyl groups $(\mathrm{C}-\mathrm{OH}$ of $\mathrm{O}=\mathrm{C}-\mathrm{OH})$ are presented at $\sim 1400 \mathrm{~cm}^{-1}$, and the band at $\sim 1044 \mathrm{~cm}^{-1}$ corresponds to the alkoxy groups (C-O) [34,56,87,92].

\subsection{Ultraviolet-Visible Spectrophotometry (UV-Vis)}

Absorption of electromagnetic radiation from the functional groups of an analyte is recorded between 190-780 nm, and is quantified through the Beer-Lambert law:

$$
\mathrm{A}=-\log \mathrm{T}=\log \left(\mathrm{I}_{0} / \mathrm{I}\right)=\varepsilon \cdot \mathrm{b} \cdot \mathrm{c}
$$

where $\mathrm{A}(-)$ is the absorption; $\mathrm{T}(-)$ is the transmittance; $\mathrm{I}_{0}$ and $\mathrm{I}$ is the incident and existing intensity of radiation; $\varepsilon\left(\mathrm{cm}^{-1} \cdot \mathrm{mol}^{-1} \cdot \mathrm{L}\right)$ is the extinction or molar absorption coefficient ranging from 1 to $5 \times 10^{5} ; \mathrm{b}(\mathrm{cm})$ is the path length; and $\mathrm{c}(\mathrm{mol} / \mathrm{L})$ is the concentration of the absorbing species. 
Absorbance and concentration have a linear relationship because $\varepsilon$ and $b$ are fixed under the experimental conditions, so quantitative analysis is obtainable for materials that obey Beer's law. The common parameters that influence the absorbance spectrum are the $\mathrm{pH}$, the temperature and the solute's concentration. Instrumentation usually involves the deuterium lamp for the ultraviolet area (190-380 nm) and the tungsten lamp for the visible area (380-780 nm); the monochromator; the blank and the solute cuvettes; and the detectors. The far UV area (below $190 \mathrm{~nm} /$ above 50,000 $\mathrm{cm}^{-1}$ ) is the area where the air oxygen absorbs, so vacuum in the chamber is required for accurate measurements. Standard solutions are used for the acquisition of the calibration curve using the wavelength of the maximum sensitivity. Proper solvents for UV-Vis measurements are those that do not absorb in these areas. Water, $95 \%$ ethanol $\left(\mathrm{CH}_{3} \mathrm{CH}_{2} \mathrm{OH}\right)$ and hexane $\left(\mathrm{CH}_{3}\left(\mathrm{CH}_{2}\right)_{4} \mathrm{CH}_{3}\right)$ are widely used. Conventional non-polar solvents are methanol $(205 \mathrm{~nm})$ and chloroform $(240 \mathrm{~nm})$. The major difference between the polar and non-polar solvents is that the former develop hydrogen bonds with the solute while the latter are more inert.

The absorption of the electromagnetic radiation derives from the structural changes of the analyte's electrons. Transitions of the valence electrons from the ground state to excited states require energy in quantized amounts. The change in the molecule's flipping dipole is responsible for the radiation-molecule interactions. The electrons are classified as $\sigma, \pi$ and $n$. The $\sigma$-electrons are strongly bonded to the nucleus and require high energies for transition, while the $\pi$ - and n- electrons are described as non-bonding and require less energy for transition (where the n-electrons require even less energy than the $\pi$-electrons). The energy amount for transition corresponds to certain areas/wavelengths; for example, the $\sigma \rightarrow \sigma^{*}$ require energy of wavelengths in the Far-UV area, the $\pi \rightarrow \pi^{*}$ and $n \rightarrow n^{*}$ transitions require energies around $200 \mathrm{~nm}$, and the $\mathrm{n} \rightarrow \pi^{*}$ transitions could be either in the UV or the visible area. It is worth mentioning that changes in the structure of the atoms (nucleus and electrons) result in changes in the required transition energy. UV-Vis spectroscopy may provide details about GO in dispersion form, in terms of its absorption and the optical band gap. The GO spectrum presents two characteristic peaks, an intense peak at $\sim 230 \mathrm{~nm}$ which corresponds to the $\pi \rightarrow \pi^{*}$ transition of the $\mathrm{sp}^{2} \mathrm{C}=\mathrm{C}$ and a minor peak/shoulder at $\sim 300 \mathrm{~nm}$ revealing the $\mathrm{n} \rightarrow \pi^{*}$ transition of the $\mathrm{C}=\mathrm{O}$ functionality [56,87-89].

\section{5. $\mathrm{N}_{2}$ Porosimetry}

The materials' surface area can be determined by physi-sorption, which is a process that involves the weak van der Waals forces $(20-50 \mathrm{~kJ} / \mathrm{mol})$ [102]. The molecules of an inert gas, such as nitrogen or argon, are adsorbed in layers allowing the calculation of the surface area and the total pore volume. The isotherm graph, that consists of the adsorption and desorption curves, provides information about the volume of the adsorbed gas per different (relative) pressures under constant mass and temperature of the adsorbent. The shape of the isotherm (type I-VI) reveals the porous morphology. The adsorbent might present micro$(<2 \mathrm{~nm})$, meso- $(2-50 \mathrm{~nm})$ and/or macro-porosity $(>50 \mathrm{~nm})$ [83]. When the gas desorption requires less relative pressures $\left(\mathrm{P} / \mathrm{P}_{0}\right)$ than those for adsorption, a hysteresis bronchus occurs. Physisorption measurements require extremely low temperatures, typically $77 \mathrm{~K}$ and a precise amount of adsorbent mass. Adsorbents with different physicochemical properties require different methods for the data evaluation [90,92]. BET, BJH and QSDFT are frequently used covering a wide range of materials. The typical specific surface area (SSA) of graphite is $\sim 6 \mathrm{~m}^{2} / \mathrm{g}$, graphene has $\sim 2600 \mathrm{~m}^{2} / \mathrm{g}$ and GO $\sim 50 \mathrm{~m}^{2} / \mathrm{g}[34,37,62,87]$.

\subsection{Atomic Force Microscopy (AFM)}

Limitations of scanning tunneling microscopy (STM/1981), such as the necessity for conductive specimens, led to the invention of atomic force microscopy (AFM/1985). Binning and Rohrer awarded the Nobel Prize in Physics for their contribution in scanning probe microscopy in 1996; and AFM has been widely used in industry since 1995. Nowadays, over 10,000 AFM-related papers are published each year. AFM is a multifunctional instrument through which the topography of a specimen can be visualized, its roughness 
becomes measurable and the identification of a composite's different phases is achievable $[34,88]$. Additionally, modern instruments allow the quantification of the surface adhesion and the electrical conductivity. The latter requires conductive tips acting as top electrodes, and relative software. Moreover, the mechanical properties such as Young's modulus and hardness can be measured by nano-indentation [44]. AFM is non-destructive and its performance is based on the balance between the sample and the probe through van der Waals forces [103]. The probe tip, with typical diameter $\sim 10 \mathrm{~nm}$, is located at the edge of a cantilever that scans the surface continuously. An aligned laser beam reflects during the lever deflection and the photodiode collects the spatial changes. The feedback system retains the deflection constant by adjusting the sample's z-position. Although the lateral resolution is strongly dependent on the tip diameter, the vertical resolution is in the Angstrom scale. Measurements can be done in air and liquid environments, but are lengthier than SEM and could last from several minutes to a couple of hours. Broadly speaking, soft samples require levers with a low spring constant. The three basic ways of operation are the non-contact mode, the tapping mode where the tip flaps the surface and the contact mode. A low oxidized GO synthesized by our group presents roughness $R_{a} \approx 3.14 \AA$ [87].

\section{Conclusions}

The appropriate synthesis of GO has many advantages in its future application. The abundance in functional groups is priceless in sorption and reinforcing applications; a less decorated GO is useful in capacitors and filtration applications, while a highly reduced GO, with similar structure to bottom-up synthesized graphene, is valuable in biosensors and electronics. A major advantage in GO synthesis is the low cost of the reactants and its availability for mass production. GO is metastable so care should be taken during the characterization. In our opinion, XRD should be the first characterization technique followed by FTIR and AFM. X-rays reveal its crystallinity through the adequate oxidation of graphite; FTIR confirms the existence of various functional groups; and AFM determines the dimensions and roughness of GO. Specification of the surface area and porosity using $\mathrm{N}_{2}$ porosimetry and investigation of impurities using EDS are also necessary. A complemental technique for GO characterization is TGA while Raman and XPS are absolutely vital for rGO characterization.

Author Contributions: Methodology, D.G.T., A.K.C., A.C.M. and G.Z.K.; writing-original draft preparation, D.G.T., A.K.C., A.C.M. and G.Z.K.; writing-review and editing, D.G.T., A.K.C., A.C.M. and G.Z.K.; Supervision, G.Z.K. All authors have read and agreed to the published version of the manuscript.

Funding: This research was funded by the Greek Ministry of Development and Investments (General Secretariat for Research and Technology) through the research project "Research-Create-Innovate", with the topic "Development of an integration methodology for the treatment of micropollutants in wastewaters and leachates coupling adsorption, advanced oxidation processes and membrane technology" (Grant No: T2E $\Delta$ K-04066).

Institutional Review Board Statement: Not applicable.

Informed Consent Statement: Not applicable.

Data Availability Statement: The raw/processed data required to reproduce these findings can be shared if required.

Conflicts of Interest: The authors declare that they have no known competing financial interest or personal relationships that could have appeared to influence the work reported in this article.

\section{References}

1. Zhang, Q.; Wu, Z.; Li, N.; Pu, Y.; Wang, B.; Zhang, T.; Tao, J. Advanced review of graphene-based nanomaterials in drug delivery systems: Synthesis, modification, toxicity and application. Mater. Sci. Eng. C 2017, 77, 1363-1375. [CrossRef]

2. Kostarelos, K.; Novoselov, K. Graphene devices for life. Nat. Nanotechnol. 2014, 9, 744-745. [CrossRef] [PubMed] 
3. Schwarzschild, B. Nobel chemistry prize goes to Curl, Kroto and Smalley for discovering fullerenes. Phys. Today 1996, $49,19$. [CrossRef]

4. Goodarzi, S.; Da Ros, T.; Conde, J.; Sefat, F.; Mozafari, M. Fullerene: Biomedical engineers get to revisit an old friend. Mater. Today 2017, 20, 460-480. [CrossRef]

5. Bendicho, C.; Bendicho-Lavilla, C.; Lavilla, I. Nanoparticle-assisted chemical speciation of trace elements. TrAC Trends Anal. Chem. 2016, 77, 109-121. [CrossRef]

6. Abella, L.; Wang, Y.; Rodríguez-Fortea, A.; Chen, N.; Poblet, J.M. Current status of oxide clusterfullerenes. Inorganica Chim. Acta 2017, 468, 91-104. [CrossRef]

7. Balch, A.L.; Winkler, K. Two-component polymeric materials of fullerenes and the transition metal complexes: A bridge between metal-organic frameworks and conducting polymers. Chem. Rev. 2016, 116, 3812-3882. [CrossRef]

8. Aderibigbe, B.; Aderibigbe, I.; Popoola, P. Design and biological evaluation of delivery systems containing bisphosphonates. Pharmaceutics 2016, 9, 2. [CrossRef]

9. Pitorre, M.; Gonde, H.; Haury, C.; Messous, M.; Poilane, J.; Bousaud, D.; Kanber, E.; Ndombina, G.A.R.; Benoit, J.P.; Bastiat, G. Recent advances in nanocarrier-loaded gels: Which drug delivery technologies against which diseases? J. Control. Release 2017, 266, 140-155. [CrossRef]

10. Gatti, T.; Menna, E.; Meneghetti, M.; Maggini, M.; Petrozza, A.; Lamberti, F. The Renaissance of fullerenes with perovskite solar cells. Nano Energy 2017, 41, 84-100. [CrossRef]

11. Rice, A.M.; Dolgopolova, E.A.; Shustova, N.B. Fulleretic materials: Buckyball- and Buckybowl-based crystalline frameworks. Chem. Mater. 2017, 29, 7054-7061. [CrossRef]

12. Mykhailiv, O.; Zubyk, H.; Plonska-Brzezinska, M. Carbon nano-onions: Unique carbon nanostructures with fascinating properties and their potential applications. Inorganica Chim. Acta 2017, 468, 49-66. [CrossRef]

13. Abbas, I.A.; Al-Amer, A.M.; Laoui, T.; Al-Marri, M.J.; Nasser, M.S.; Khraisheh, M.; Atieh, M.A. Heavy metal removal from aqueous solution by advanced carbon nanotubes: Critical review of adsorption applications. Sep. Purif. Technol. 2016, 157, $141-161$.

14. Gupta, V.K.; Moradi, O.; Tyagi, I.; Agarwal, S.; Sadegh, H.; Shahryari-Ghoshekandi, R.; Makhlouf, A.S.H.; Goodarzi, M.; Garshasbi, A. Study on the removal of heavy metal ions from industry waste by carbon nanotubes: Effect of the surface modification: A review. Crit. Rev. Environ. Sci. Technol. 2015, 46, 93-118. [CrossRef]

15. Hollanda, L.; Lobo, A.; Lancellotti, M.; Berni, E.; Corat, E.; Zanin, H. Graphene and carbon nanotube nanocomposite for gene transfection. Mater. Sci. Eng. C 2014, 39, 288-298. [CrossRef]

16. Wang, H.; Kakade, B.A.; Tamaki, T.; Yamaguchi, T. Synthesis of 3D graphite oxide-exfoliated carbon nanotube carbon composite and its application as catalyst support for fuel cells. J. Power Sources 2014, 260, 338-348. [CrossRef]

17. Kumar, R.; Chawla, J.; Kaur, I. Removal of cadmium ion from wastewater by carbon-based nanosorbents: A review. J. Water Health 2014, 13, 18-33. [CrossRef]

18. Alsharef, J.; Taha, M.R.; Khan, T.A. Physical dispersion of nanocarbons in composites-A Review. J. Teknol. 2017, 79, 69-81. [CrossRef]

19. Nupearachchi, C.; Mahatantila, K.; Vithanage, M. Application of graphene for decontamination of water; Implications for sorptive removal. Groundw. Sustain. Dev. 2017, 5, 206-215. [CrossRef]

20. Zhang, H.; Chen, N.; Sun, C.; Luo, X. Investigations on physicochemical properties and electrochemical performance of graphite felt and carbon felt for iron-chromium redox flow battery. Int. J. Energy Res. 2020, 44, 3839-3853. [CrossRef]

21. Zhang, H.; Tan, Y.; Luo, X.; Sun, C.; Chen, N. Polarization effects of a rayon and polyacrylonitrile based graphite felt for iron-chromium redox flow batteries. ChemElectroChem 2019, 6, 3175-3188. [CrossRef]

22. Inagaki, M.; Kaburagi, Y.; Hishiyama, Y. Thermal management material: Graphite. Adv. Eng. Mater. 2014, 16, 494-506. [CrossRef]

23. de Oliveira, E.H.C.; Fraga, D.M.D.S.M.; da Silva, M.P.; Fraga, T.J.M.; Carvalho, M.N.; Freire, E.M.P.D.L.; Ghislandi, M.G.; Sobrinho, M.A.D.M. Removal of toxic dyes from aqueous solution by adsorption onto highly recyclable $\mathrm{xGnP}^{\circledR}$ graphite nanoplatelets. J. Environ. Chem. Eng. 2019, 7, 103001. [CrossRef]

24. Peierls, R. Quelques proprietes typiques des corps solides. Ann. L'institut Henri Poincare 1935, 5, 177-222.

25. Landau, L.D. Zur theorie der phase numwandlungen II. Phys. Z. Sowjetunion 1937, 11, $26-35$.

26. Wallace, P.R. The band theory of graphite. Phys. Rev. 1947, 71, 622-634. [CrossRef]

27. Novoselov, K.S.; Geim, A.K.; Morozov, S.V.; Jiang, D.; Zhang, Y.; Dubonos, S.V.; Grigorieva, I.V.; Firsov, A.A. Electric field effect in atomically thin carbon films. Science 2004, 306, 666-669. [CrossRef] [PubMed]

28. Molina, J.; Cases, F.; Moretto, L. Graphene-based materials for the electrochemical determination of hazardous ions. Anal. Chim. Acta 2016, 946, 9-39. [CrossRef]

29. Randviir, E.P.; Brownson, D.; Banks, C.E. A decade of graphene research: Production, applications and outlook. Mater. Today 2014, 17, 426-432. [CrossRef]

30. Compton, O.C.; Jain, B.; Dikin, D.A.; Abouimrane, A.; Amine, K.; Nguyen, S. Chemically active reduced graphene oxide with tunable C/O ratios. ACS Nano 2011, 5, 4380-4391. [CrossRef]

31. Hussain, A.; Mehdi, S.M.; Abbas, N.; Hussain, M.; Naqvi, R.A. Synthesis of graphene from solid carbon sources: A focused review. Mater. Chem. Phys. 2020, 248, 122924. [CrossRef] 
32. Shen, Y.; Fang, Q.; Chen, B. Environmental applications of three-dimensional graphene-based macrostructures: Adsorption, transformation, and detection. Environ. Sci. Technol. 2014, 49, 67-84. [CrossRef]

33. Del Castillo, E.; Cargnoni, F.; Soave, R.; Trioni, I.M. Spin-polarized charge transfer induced by transition metal adsorption on graphene. Phys. Scr. 2016, 91, 53007. [CrossRef]

34. Lee, X.J.; Hiew, B.Y.Z.; Lai, K.C.; Lee, L.Y.; Gan, S.; Thangalazhy-Gopakumar, S.; Rigby, S. Review on graphene and its derivatives: Synthesis methods and potential industrial implementation. J. Taiwan Inst. Chem. Eng. 2018, 98, 163-180. [CrossRef]

35. Papageorgiou, D.; Kinloch, I.A.; Young, R.J. Mechanical properties of graphene and graphene-based nanocomposites. Prog. Mater. Sci. 2017, 90, 75-127. [CrossRef]

36. Singh, Z.S. Applications and toxicity of graphene family nanomaterials and their composites. Nanotechnol. Sci. Appl. 2016, 9, 15-28. [CrossRef]

37. Wang, H.; Hu, Y.H. Effect of oxygen content on structures of graphite oxides. Ind. Eng. Chem. Res. 2011, 50, 6132-6137. [CrossRef]

38. Karu, A.E.; Beer, M. Pyrolytic formation of highly crystalline graphite films. J. Appl. Phys. 1966, 37, 2179-2181. [CrossRef]

39. Land, T.; Michely, T.; Behm, R.; Hemminger, J.; Comsa, G. STM investigation of single layer graphite structures produced on $\mathrm{Pt}(111)$ by hydrocarbon decomposition. Surf. Sci. 1992, 264, 261-270. [CrossRef]

40. Somani, P.R.; Somani, S.P.; Umeno, M. Planer nano-graphenes from camphor by CVD. Chem. Phys. Lett. 2006, 430, 56-59. [CrossRef]

41. Lim, J.Y.; Mubarak, N.; Abdullah, E.C.; Nizamuddin, S.; Khalid, M. Inamuddin Recent trends in the synthesis of graphene and graphene oxide based nanomaterials for removal of heavy metals-A review. J. Ind. Eng. Chem. 2018, 66, 29-44. [CrossRef]

42. Nawz, T.; Safdar, A.; Hussain, M.; Lee, D.S.; Siyar, M. Graphene to advanced MoS2: A review of structure, synthesis, and optoelectronic device application. Crystals 2020, 10, 902. [CrossRef]

43. Bae, S.; Kim, H.; Lee, Y.; Xu, X.; Park, J.-S.; Zheng, Y.; Balakrishnan, J.; Lei, T.; Kim, H.R.; Song, Y.I.; et al. Roll-to-roll production of 30-inch graphene films for transparent electrodes. Nat. Nanotechnol. 2010, 5, 574-578. [CrossRef]

44. Saeed, M.; Alshammari, Y.; Majeed, S.A.; Al-Nasrallah, E. Chemical vapour deposition of graphene-Synthesis, characterisation, and applications: A review. Molecules 2020, 25, 3856. [CrossRef]

45. Dimiev, A.; Kosynkin, D.V.; Alemany, L.B.; Chaguine, P.; Tour, J.M. Pristine graphite oxide. J. Am. Chem. Soc. 2012, 134, $2815-2822$. [CrossRef]

46. Brodie, B.C. On the atomic weight of graphite. Philos. Trans. 1859, 149, 249-259.

47. Schafhaeutl, C. On the combination of carbon with silicon and iron, and other metals, forming the different species of cast iron, steel, and malleable iron. Philos. Mag. 1840, 16, 570-590.

48. Staudenmaier, L. Verfahren zur darstellung der graphitsäure. Eur. J. Inorg. Chem. 1898, 31, 1481-1487. [CrossRef]

49. Hummers, W.S.; Offeman, R.E. Preparation of graphitic oxide. J. Am. Chem. Soc. 1958, 80, 1339. [CrossRef]

50. Charpy, G. Sur la formation de l'oxyde graphitique et la d'efnition du graphite. C. R. Hebd. Seances Acad. Sci. 1909, 148, 920-923.

51. Scholz, W.; Boehm, H.P. Untersuchungen am graphitoxid. VI. Betrachtungen zur struktur des graphitoxids. J. Inorg. Gen. Chem. 1969, 369, 327-340. [CrossRef]

52. Matuyama, E. Pyrolysis of graphitic acid. J. Phys. Chem. 1954, 58, 215-219. [CrossRef]

53. Hiew, B.Y.Z.; Lee, L.Y.; Lee, X.J.; Gopakumar, S.T.; Gan, S.; Lim, S.S.; Pan, G.T.; Yang, T.C.K.; Chiu, W.S.; Khiew, P.S. Review on synthesis of 3D graphene-based configurations and theiradsorption performance for hazardous water pollutants. Process. Saf. Environ. Prot. 2018, 116, 262-286. [CrossRef]

54. Marcano, D.C.; Kosynkin, D.V.; Berlin, J.M.; Sinitskii, A.; Sun, Z.; Slesarev, A.; Alemany, L.B.; Lu, W.; Tour, J.M. Improved synthesis of graphene oxide. ACS Nano 2010, 4, 4806-4814. [CrossRef]

55. Dimiev, A.M.; Eigler, S. Graphene Oxide: Fundamentals and Applications, 1st ed.; John Wiley \& Sons: Hoboken, NJ, USA, 2017 ; p. 454.

56. Chen, J.; Yao, B.; Li, C.; Shi, G. An improved Hummers method for eco-friendly synthesis of graphene oxide. Carbon 2013, 64, 225-229. [CrossRef]

57. Thiele, H. Graphit und graphitsäure. J. Inorg. Gen. Chem. 1930, 190, 145-160. [CrossRef]

58. Lerf, A.; He, H.; Riedl, T.; Forster, M.; Klinowski, J. 13C and 1H MAS NMR studies of graphite oxide and its chemically modified derivatives. Solid State Ionics 1997, 101-103, 857-862. [CrossRef]

59. Eigler, S.; Enzelberger-Heim, M.; Grimm, S.; Hofmann, P.; Kroener, W.; Geworski, A.; Dotzer, C.; Röckert, M.; Xiao, J.; Papp, C.; et al. Wet chemical synthesis of graphene. Adv. Mater. 2013, 25, 3583-3587. [CrossRef]

60. Rouf, T.B.; Kokini, J.L. Biodegradable biopolymer-graphene nanocomposites. J. Mater. Sci. 2016, 51, 9915-9945. [CrossRef]

61. Pei, S.; Cheng, H.M. The reduction of graphene oxide. Carbon 2012, 50, 3210-3228. [CrossRef]

62. Zhao, B.; Liu, P.; Jiang, Y.; Pan, D.; Tao, H.; Song, J.; Fang, T.; Xu, W. Supercapacitor performances of thermally reduced graphene oxide. J. Power Sources 2012, 198, 423-427. [CrossRef]

63. Chen, J.; Li, Y.; Huang, L.; Li, C.; Shi, G. High-yield preparation of graphene oxide from small graphite flakes via an improved Hummers method with a simple purification process. Carbon 2015, 81, 826-834. [CrossRef]

64. Wang, Y.; Guo, L.; Qi, P.; Liu, X.; Wei, G. Synthesis of three-dimensional graphene-based hybrid materials for water purification: A review. Nanomaterials 2019, 9, 1123. [CrossRef] [PubMed]

65. Liu, X.; Chen, G.; Bao, J.; Xu, X. General preparation and shaping of multifunctional nanowire aerogels for pressure/gas/photosensing. Adv. Fiber Mater. 2021, in press. [CrossRef] 
66. Chang, D.; Liu, J.; Fang, B.; Xu, Z.; Li, Z.; Liu, Y.; Brassart, L.; Guo, F.; Gao, W.; Gao, C. Reversible fusion and fission of graphene oxide-based fibers. Science 2021, 372, 614-617. [CrossRef] [PubMed]

67. Li, P.; Cheng, C.; Shen, K.; Zhang, T.; Wang, X.; Hsiao, B.S. Enhancing dehydration performance of isopropanol by introducing intermediate layer into sodium alginate nanofibrous composite pervaporation membrane. Adv. Fiber Mater. 2019, 1, 137-151. [CrossRef]

68. Boehm, H.-P.; Clauss, A.; Hofmann, U. Graphite oxide and its membrane properties. J. Chim. Phys. 1961, 58, 141-147. [CrossRef]

69. Nair, R.R.; Wu, H.A.; Jayaram, P.N.; Grigorieva, I.V.; Geim, A.K. Unimpeded permeation of water through helium-leak-tight graphene-based membranes. Science 2012, 335, 442-444. [CrossRef]

70. Boehm, H.P.; Clauss, A.; Fischer, G.; Hofmann, U. Proceedings of the Fifth Conference on Carbon; Pergamon Press: Oxford, UK, 1962.

71. Mohan, V.B.; Lau, K.-T.; Hui, D.; Bhattacharyya, D. Graphene-based materials and their composites: A review on production, applications and product limitations. Compos. Part B Eng. 2018, 142, 200-220. [CrossRef]

72. Zhang, C.; Lv, W.; Xie, X.; Tang, D.; Liu, C.; Yang, Q.-H. Towards low temperature thermal exfoliation of graphite oxide for graphene production. Carbon 2013, 62, 11-24. [CrossRef]

73. Gudarzi, M.M.; Moghadam, M.H.M.; Sharif, F. Spontaneous exfoliation of graphite oxide in polar aprotic solvents as the route to produce graphene oxide-organic solvents liquid crystals. Carbon 2013, 64, 403-415. [CrossRef]

74. Botas, C.; Álvarez, P.; Blanco, C.; Santamaria, R.; Granda, M.; Gutiérrez, D.; Rodriguez-Reinoso, F.; Menéndez, R. Critical temperatures in the synthesis of graphene-like materials by thermal exfoliation-reduction of graphite oxide. Carbon 2012, 52, 476-485. [CrossRef]

75. Kohlschütter, V.; Haenni, P. Zur kenntnis des graphitischen kohlenstoffs und der graphitsäure. J. Inorg. Gen. Chem. 1919, 105, 121-144. [CrossRef]

76. Hofmann, U.; Frenzel, A. The reduction of graphite oxide with hydrogen sulphide. Kolloid-Zeitschrift 1934, 68, 149-151. [CrossRef]

77. Vermisoglou, E.; Giannakopoulou, T.; Romanos, G.; Boukos, N.; Giannouri, M.; Lei, C.; Lekakou, C.; Trapalis, C. Non-activated high surface area expanded graphite oxide for supercapacitors. Appl. Surf. Sci. 2015, 358, 110-121. [CrossRef]

78. Guan, F.; Han, Z.; Jin, M.; Wu, Z.; Chen, Y.; Chen, S.; Wang, H. Durable and flexible bio-assembled RGO-BC/BC bilayer electrodes for pressure sensing. Adv. Fiber Mater. 2021, 3, 128-137. [CrossRef]

79. Zhang, Y.-L.; Guo, L.; Xia, H.; Chen, Q.-D.; Feng, J.; Sun, H.-B. Photoreduction of graphene oxides: Methods, properties, and applications. Adv. Opt. Mater. 2013, 2, 10-28. [CrossRef]

80. Valipour, A.; Hamnabard, N.; Ahn, Y.-H. Performance evaluation of highly conductive graphene (RGOHI-AcOH) and graphene/metal nanoparticle composites (RGO/Ni) coated on carbon cloth for supercapacitor applications. RSC Adv. 2015, 5, 92970-92979. [CrossRef]

81. Yang, H.; Cao, Y.; He, J.; Zhang, Y.; Jin, B.; Sun, J.-L.; Wang, Y.; Zhao, Z. Highly conductive free-standing reduced graphene oxide thin films for fast photoelectric devices. Carbon 2017, 115, 561-570. [CrossRef]

82. Wang, Y.; Chen, Y.; Lacey, S.D.; Xu, L.; Xie, H.; Li, T.; Danner, V.A.; Hu, L. Reduced graphene oxide film with record-high conductivity and mobility. Mater. Today 2017, 21, 186-192. [CrossRef]

83. Yun, S.; Kang, S.-O.; Park, S.; Park, H.S. CO2-activated, hierarchical trimodal porous graphene frameworks for ultrahigh and ultrafast capacitive behavior. Nanoscale 2014, 6, 5296-5302. [CrossRef]

84. Peng, W.; Li, H.; Liu, Y.; Song, S. A review on heavy metal ions adsorption from water by graphene oxide and its composites. J. Mol. Liq. 2017, 230, 496-504. [CrossRef]

85. Harris, W.; White, N.G. X-ray diffraction techniques for soil mineral identification. In Methods of Soil Analysis Part 5-Mineralogical Methods, 5.5; Soil Science Society of America, Inc.: New York, NY, USA, 2008; pp. 81-115.

86. Ioelovich, M. Crystallinity and hydrophility of chitin and chitosan. Res. Rev. J. Chem. 2014, 3, 7-14.

87. Trikkaliotis, D.G.; Mitropoulos, A.C.; Kyzas, G.Z. Low-cost route for top-down synthesis of over- and low-oxidized graphene oxide. Colloids Surf. A Physicochem. Eng. Asp. 2020, 600, 124928. [CrossRef]

88. Chen, H.; Du, W.; Liu, J.; Qu, L.; Li, C. Efficient room-temperature production of high-quality graphene by introducing removable oxygen functional groups to the precursor. Chem. Sci. 2018, 10, 1244-1253. [CrossRef] [PubMed]

89. Johra, F.T.; Lee, J.-W.; Jung, W.-G. Facile and safe graphene preparation on solution based platform. J. Ind. Eng. Chem. 2014, 20, 2883-2887. [CrossRef]

90. Gurzeda, B.; Buchwald, T.; Nocun, M.; Bakowicz, A.; Krawczyk, P. Graphene material preparation through thermal treatment of graphite oxide electrochemically synthesized in aqueous sulfuric acid. RSC Adv. 2017, 7, 19904-19911. [CrossRef]

91. Kyzas, G.Z.; Bikiaris, D.N.; Deliyanni, E.A. Advanced low-swelling chitosan/graphite oxide-based biosorbents. Mater. Lett. 2014, 128, 46-49. [CrossRef]

92. Ossonon, B.D.; Bélanger, D. Synthesis and characterization of sulfophenyl-functionalized reduced graphene oxide sheets. RSC Adv. 2017, 7, 27224-27234. [CrossRef]

93. Dimiev, A.; Tour, J. Mechanism of graphene oxide formation. ACS Nano 2014, 8, 3060-3068. [CrossRef]

94. Shen, B.; Lu, D.; Zhai, W.; Zheng, W. Synthesis of graphene by low-temperature exfoliation and reduction of graphite oxide under ambient atmosphere. J. Mater. Chem. C 2013, 1, 50-53. [CrossRef]

95. Andersson, P.O.; Viberg, P.; Forsberg, P.; Nikolajeff, F.; Österlund, L.; Karlsson, M. Nanocrystalline diamond sensor targeted for selective CRP detection: An ATR-FTIR spectroscopy study. Anal. Bioanal. Chem. 2016, 408, 3675-3680. [CrossRef] [PubMed] 
96. Fale, P.L.V.; Chan, A.K.L. Preventing damage of germanium optical material in attenuated total reflection-Fourier transform infrared (ATR-FTIR) studies of living cells. Vib. Spectrosc. 2017, 91, 59-67. [CrossRef]

97. Farinas, K.C.; Doh, L.; Venkatraman, S.; Potts, R.O. Characterization of solute diffusion in a polymer using ATR-FTIR spectroscopy and bulk transport techniques. Macromolecules 1994, 27, 5220-5222. [CrossRef]

98. Ivanov, D.; Dubreuil, N.; Raussens, V.; Ruysschaert, J.M.; Goormaghtigh, E. Evaluation of the ordering of membranes in multilayer stacks built on an ATR-FTIR germanium crystal with atomic force microscopy: The case of the $\mathrm{H}^{+}, \mathrm{K}^{+}$-ATPase-containing gastric tubulovesicle membranes. Biophys. J. 2004, 87, 1307-1315. [CrossRef] [PubMed]

99. Devouge, S.; Conti, J.; Goldsztein, A.; Gosselin, E.; Brans, A.; Voué, M.; De Coninck, J.; Homblé, F.; Goormaghtigh, E.; MarchandBrynaert, J. Surface functionalization of germanium ATR devices for use in FTIR-biosensors. J. Colloid Interface Sci. 2009, 332, 408-415. [CrossRef]

100. Guiliano, M.; Asia, L.; Onoratini, G.; Mille, G. Applications of diamond crystal ATR FTIR spectroscopy to the characterization of ambers. Spectrochim. Acta Part A Mol. Biomol. Spectrosc. 2007, 67, 1407-1411. [CrossRef] [PubMed]

101. Edelmann, A.; Diewok, J.; Baena, J.R.; Lendl, B. High-performance liquid chromatography with diamond ATR-FTIR detection for the determination of carbohydrates, alcohols and organic acids in red wine. Anal. Bioanal. Chem 2003, 376, 92-97. [CrossRef] [PubMed]

102. Sotomayor, F.J.; Cychosz, K.A.; Thommes, M. Characterization of micro/mesoporous materials by physisorption: Concepts and case studies. Acc. Mater. Surf. Res. 2018, 3, 34-50.

103. Avila, A.; Bhushan, B. Electrical measurement techniques in atomic force microscopy. Crit. Rev. Solid State Mater. Sci. 2010, 35, 38-51. [CrossRef] 